\title{
Métodos Estatísticos para a análise de bibliotecas digitais de expressão gênica
}

\author{
Leonardo Varuzza
}

\author{
Tese Apresentada ao \\ Programa Interunidades \\ DE BioinformáticA DA \\ Universidade de São Paulo \\ COMO PARTE DOS REQUISITOS \\ PARA OBTENÇÃO DO GRAU DE \\ Doutor de Bioinformática
}

Orientador: Carlos Alberto de Bragança Pereira

\author{
Versão 1.1
}

São Paulo - Setembro de 2008 


\section{Agradecimentos}

Agradeço ao meu orientador Prof. Carlos Alberto de Bragança Pereira, que tornou a realização desta tese possível. Também agradeço meu colega Ricardo Vêncio, pelo grande auxílio neste trabalho, e ao meu primeiro orientador, Prof. Arthur Gruber. Agradecimento especial para a minha esposa Sílvia, pelo apoio e pela revisão do texto.

\section{Banca Examinadora}

Carlos Alberto de Bragança Pereira

Paulo Sergio Lopes de Oliveira

Heleno Bolfarine

Eloísa Helena Tajara da Silva

Zanoni Diaz 


\section{Sumário}

1 Introdução 9

1.1 Expressão Gênica . . . . . . . . . . . . . . . . . . . . . . 11

1.2 A descoberta do DNA . . . . . . . . . . . . . . . . . 11

1.2.1 Dogma central da Biologia Molecular . . . . . . . . . . . . . 12

1.2.2 Rede complexa de genes . . . . . . . . . . . . . . . . . . . 15

1.2.3 Medição do nível de mRNA . . . . . . . . . . . . . . . . . . 17

1.3 Objetivos . . . . . . . . . . . . . . . . . . . . . 19

1.4 Convenções Utilizadas . . . . . . . . . . . . . . . . . . . . . . . . . 20

2 Modelagem Probabilística da Contagem de Transcritos 21

2.1 Os dados . . . . . . . . . . . . . . . . . . . . . . . . 21

2.2 Modelo Multinomial . . . . . . . . . . . . . . . . . . . . . 24

2.2.1 Distribuição a posteriori do parâmetro $\mathbf{P} \ldots \ldots \ldots$. . . . . . 24

2.2 .2 Priori Conjugada Natural . . . . . . . . . . . . . . . . . 25

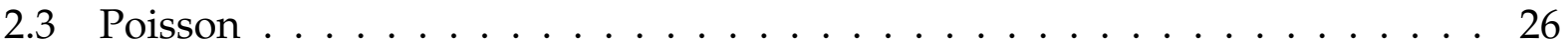

2.3.1 Probabilidade conjunta de diversas Poissons . . . . . . . . . . . 27

3 Kemp: Teste Estatístico Clássico para a Comparação da expressão de Tags 29

3.1 Teste de Significância . . . . . . . . . . . . . . . . . . . . . . . 30

3.1 .1 Cálculo do Nível de Significância . . . . . . . . . . . . . . . 32 
3.2 Cálculo automático do nível crítico . . . . . . . . . . . . . . . 34

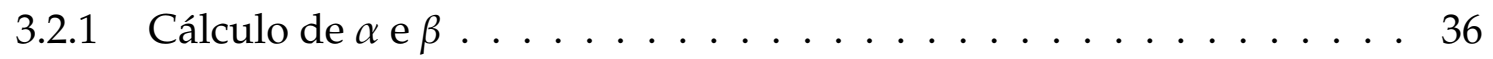

3.3 Implementação . . . . . . . . . . . . . . . . . . . . . . . . 39

3.3.1 Consistência do teste em relação à remoção de tags de baixa contagem 40

3.4 Outros testes de significância $\ldots \ldots \ldots$. . . . . . . . . . . 40

3.4 .1 Audic e Claverie . . . . . . . . . . . . . . . . . . . . . . 41

3.4.2 Método Bayesiano de Chen . . . . . . . . . . . . . . . . 41

3.4.3 Estatística R de Stekel . . . . . . . . . . . . . . . . . . . . . . . 42

3.4.4 Teste do $\chi^{2}$ de homogeneidade . . . . . . . . . . . . . 43

3.4.5 O teste proposto Kemp em relação à outros testes . . . . . . . . . . . 44

3.5 Aplicações . . . . . . . . . . . . . . . . . . . . . . . 44

3.5.1 Tecidos de tumores de cabeça e pescoço . . . . . . . . . . . . . . 44

4 Basu: Teste Estatístico Bayesiano para a Comparação da expressão de Tags 47

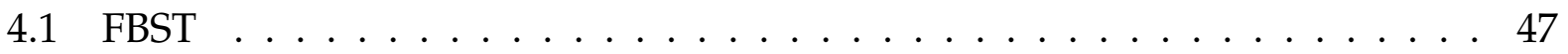

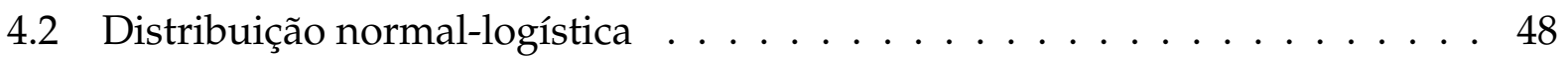

4.3 Comparação entre os níveis de significância freqüentista e bayesiano . . . . 50

5 Agrupamentos de Bibliotecas

5.1 Agrupamentos . . . . . . . . . . . . . . . . . . 54

5.1 .1 Agrupamento por particionamento . . . . . . . . . . 55

5.1 .2 Agrupamento Hierárquico $\ldots \ldots \ldots$. . . . . . . . . 56

5.1 .3 Análise de componentes principais (PCA) . . . . . . . . . . 58

5.2 O espaço Simplex . . . . . . . . . . . . . . . . . . . . . . . 59

5.2.1 Composições e o espaço simplex . . . . . . . . . . . . . . . . . . . 59

5.2.2 Estrutura de covariância em composições . . . . . . . . . . . . . . . 61

5.3 Uma métrica para o espaço simplex . . . . . . . . . . . . . . . . . . 62

5.4 Implementação $\ldots \ldots \ldots \ldots$. . . . . . . . . . . . . . . . . . 64 
5.5 Aplicações . . . . . . . . . . . . . . . . . . . . . . 66

5.5.1 Agrupamento hierárquico de bibliotecas de tecidos cerebrais . . . 66

5.5.2 Análise de agrupamento de dados relativos à doença de Alzheimer . 66

5.5.3 Agrupamento de dados com tags pré-selecionadas . . . . . . . . 70

5.5 .4 Northern Digital . . . . . . . . . . . . . . . . . . 70

6 Considerações Finais $\quad 75$

6.1 Conclusão . . . . . . . . . . . . . . . . . . . . . . . . . . 75

6.2 Outros trabalhos . . . . . . . . . . . . . . . . . . . . 77

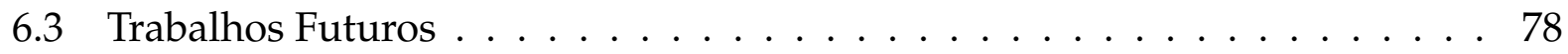




\section{Capítulo 1}

\section{Introdução}

Esta tese trata da aplicação de técnicas de estatística para a resolução de problemas encontrados na análise de dados provenientes da área de biologia molecular - mais especificamente, dados gerados por estudos de expressão gênica obtidos pela contagem de transcritos, também chamados de perfis digitais de expressão. Esta contagem pode ser realizada por meio de técnicas tais como EST[75], SAGE[87], MPSS[17], ou de qualquer outro método de contagem que venha a surgir[65]. Nestes métodos, o resultado é uma lista de tags ${ }^{1}$ com suas respectivas contagems, ou seja, uma tabela de freqüências, e que é chamada de biblioteca de tags, ou perfil digital de expressão (digital expression profile).

É de especial interesse conjuntos de bibliotecas feitos de forma a elucidar uma questão biológica, como por exemplo descobrir genes ligados à um tumor, ou então, comparar perfis gerados apartir de diferentes tumores. Nesses casos pode-se analisar um conjunto formado por uma biblioteca extraída de um tecido tumoral e outra extraída de um tecido normal, ou ainda, um conjunto com bibliotecas de tecidos tumorais com diferentes gradações de malignidade, e assim por diante.

O objetivo desta tese aperfeiçoar as técnicas de análise de bibliotecas digitais de expressão gênica através da melhorias na modelagem estatística das freqüências observadas.

\footnotetext{
${ }^{1}$ No texto o termo tag será empregado em um sentido amplo para se referir tando às tags de SAGE, quando assinaturas de MPSS ou até leituras (reads) de EST. Não será utilizado o termo traduzido etiqueta, pois ele não é de uso corrente na área de Biologia Molecular ou Bioinformática.
} 
Mais particularmente, pretendemos estudar conjundos de bibliotecas de expressão das seguintes maneiras:

- Desenvolver e implementar testes de significância para identificar tags diferencialmente expressas em conjuntos de bibliotecas digitais de expressão gênica, que não dependam de resultados assintóticos, e portanto, possam ser aplicados para todas as tags independentemente do seu nível de expressão.

- Criar uma aplicação que permita o uso da distância de Aitchison em análises de agrupamento baseadas em distância, como agrupamento hierárquico, k-médias e kmedóides. Assim como analisar o desempenho desta medida de distância em dados reais.

Usualmente o conjunto de dados das bibliotecas que serão estudadas é organizado em uma matriz, com as linhas representados a freqüência de cada tag e as colunas as freqüências de cada biblioteca. As técnicas que serão abordadas analisam a matriz de dados nos dois eixos: na primeira são submetidos à análise os dados linha por linha, à procura de tags que tenham freqüências significativamente diferentes, pois essa é uma indicação de que essas tags podem estar envolvidas no processo biológico de interesse; as colunas da matriz serão analisadas pelas técnicas de agrupamento por distância, propondo-se para este fim o uso da distância de Aitchison[3]. A análise de agrupamentos responde às seguintes perguntas: 'Dentre as amostras obtidas, quais são as que se assemelham mais?' e 'Os tumores do córtex cerebral são mais similares entre si do que os outros tumores?'.

No restante da introdução, serão apresentados os conceitos biológicos essenciais à compreensão do problema. De forma alguma essa introdução será completa, e para mais informações sugere-se o livro Genomes[19]. No capítulo 2, os dados serão estudados de maneira mais detalhada, e seus aspectos estatísticos serão explorados. Também haverá discussões acerca de alguns resultados básicos relacionados às distribuições de probabilidade relevantes ao trabalho. Nos capítulos 3,4 e 5, os métodos propostos serão discutidos 
em profundidade, e os resultados da aplicação dos métodos serão mostrados.

\subsection{Expressão Gênica}

Nesta seção, pretendemos introduzir os conceitos básicos de biologia molecular necessários ao entendimento da tese. Será explicado o processo de transmissão de informações do DNA até as proteínas.

\subsection{A descoberta do DNA}

Cada célula de um ser vivo é um sistema extremamente complexo. Ela reage ao ambiente, faz cópias de si mesma e transmite as suas características para as suas respectivas cópias. Mas como a célula, uma estrutura de normalmente $10 \mu m$, consegue coordenar todas as suas funções? Hoje sabemos que a célula funciona coordenada por um código de quatro símbolos, ordenados em um longo polímero de DNA, o ácido desoxirribonucleico. Mas o funcionamento do DNA demorou quase 100 anos para ser descoberto. Os primeiros passos remontam à teoria da evolução das espécies de Charles Darwin, de 1859[34], e ao estudo dos caracteres hereditários de Gregor Mendel, de 1866[69].

Em paralelo aos trabalhos desses dois pioneiros, as bases biológicas do processo de evolução e hereditariedade foram sendo elucidadas. O DNA foi descoberto na Alemanha em 1869 por Firedrich Miescher[33]. Quase na mesma época, Walther Flemming observou a divisão celular no microscópio e descobriu a cromatina e os cromossomos. Suas constatações foram publicadas em 1882[46]. Mas, como a teoria de Mendel permaneceu desconhecida até o final do século XIX, Flemming não associou o cromossomo aos caracteres hereditários. Essa associação só se realizaria em 1902, dois anos após a redescoberta dos estudos de Mendel, e seria feita de forma independente por Boveri e Sutton[50].

O papel do DNA foi comprovado pelos experimentos de Avery[11], em 1944, na Universidade de Columbia, e de Hershey e Chase[53], em 1952, no Cold Spring Harbor 
Laboratory, ambos em Nova Iorque. Em 1953, Watson e Crick, baseando-se no trabalho de Rosalind Franklin, elucidaram a estrutura do DNA e sugeriram o mecanismo de duplicação do DNA por pareamento de bases complementares[92].

Estabelecido que o DNA era o vetor da informação hereditária, faltava ainda determinar como a informação do DNA era transformada em proteínas. O artigo de Watson e Crick teve grande impacto sobre o físico George Gamow, que começou a pesquisar o código que relaciona o DNA aos aminoácidos das proteínas. Ele publicou suas primeiras idéias em uma carta para a revista Nature em 1954, e depois, em um artigo para o Preccedinds of the National Academy, mas este foi recusado porque Gamow incluiu como co-autor o personagem de seus livros de divulgação científica G. G. H Tompkins. O artigo foi finalmente publicado pela Royal Danish Academy, com o autor imaginário devidamente suprimido. Gamow também criou o grupo "RNA Tie Club", com 20 membros (um para cada aminoácido), de pessoas interessadas no problema do código genético. Entre os membros estava o próprio Crick, que se tornara amigo de Gamow[32]. Crick encontrou problemas no código proposto por Gamow, e por mais 12 anos discutiu-se qual seria o código genético correto. O código só foi descoberto em 1961 por Matthaei e Nirenberg[68, 67], enquanto trabalhavam no NIH (National Institute of Health).

O código genético foi a última peça que faltava para explicar o mecanismo de transmissão de informações entre as gerações e sua transformação em proteínas. No final dos anos 60, estava claro que o DNA era o princípio fundamental do funcionamento das células, mas faltava esclarecer de que maneira uma seqüência de somente quatro símbolos poderia proporcionar toda a complexidade dos seres vivos.

\subsubsection{Dogma central da Biologia Molecular}

O DNA nuclear encontra-se enrolado em estruturas denominadas cromossomos. Dentro de cada cromossomo existem regiões especiais chamadas de genes, os quais são de profundo interesse biológico, pois as informações neles contidas são suficientes para a 
produção de proteínas, que são moléculas responsáveis pela estrutura e pelas reações químicas necessárias ao funcionamento das células.

Tanto o DNA quanto as proteínas são macromoléculas formadas por uma grande quantidade de poucos elementos que se repetem. O DNA é formado por apenas quatro elementos diferentes, chamados de bases nitrogenadas. Estas são a Guanina, Citosina, Timina e Adenina, representadas pelas iniciais: G, C, T e A. Devido a natureza linear da molécula de DNA, é possível representar facilmente qualquer trecho do DNA como uma cadeia de caracteres, um para cada base nitrogenada. Por exemplo, AAT representa uma molécula formada pela seqüência de duas moléculas de Adenina seguidas por uma molécula de Timina.

Os elementos que formam as proteínas são os aminoácidos. Existe um total de 20 aminoácidos diferentes, que podem ser representados por uma abreviação de três letras ou uma letra. A lista dos aminoácidos está disponível na tabela 1.1.

\begin{tabular}{lll|lll} 
Nome & Símbolo & Abreviação & Nome & Símbolo & Abreviação \\
\hline \hline Glicina & Gly, Gli & G & Tirosina & Tyr, Tir & Y \\
Alanina & Ala & A & Asparagina & Asn & N \\
Leucina & Leu & L & Glutamina & Gln & Q \\
Valina & Val & V & Aspartato & Asp & D \\
Isoleucina & Ile & I & Glutamato & Glu & E \\
Prolina & Pro & P & Arginina & Arg & R \\
Fenilalanina & Phe, Fen & F & Lisina & Lys, Lis & K \\
Serina & Ser & S & Histidina & His & H \\
Treonina & Thr, The & T & Triptofano & Trp, Tri & W \\
Cisteina & Cys, Cis & C & Metionina & Met & M \\
\hline
\end{tabular}

Tabela 1.1: Lista dos aminoácidos e seus respectivos símbolos.

A informação da seqüência de bases do DNA está ligada à seqüência de aminoácidos através do código genético, que associa cada tripla de bases, denominadas códons, a um dos aminoácidos e ao sinal que indica o fim do gene (veja tabela 1.2). É fácil notar que existe um problema no código genético, pois os códons podem codificar $4^{3}=64$ aminoácidos diferentes, mas na natureza só se observam 20 aminoácidos e um sinal indicando o fim da proteína (stop codon). A natureza resolveu este problema tornando o código genético 
degenerado, pois cada aminoácido corresponde a mais de um códon.

\begin{tabular}{ll|ll|ll|ll}
\hline TTT & Phe & TCT & Ser & TAT & Tyr & TGT & Cys \\
TTC & Phe & TCC & Ser & TAC & Tyr & TGC & Cys \\
TTA & Leu & TCA & Ser & TAA & FIM & TGA & FIM \\
TTG & Leu & TCG & Ser & TAG & FIM & TGG & Trp \\
CTT & Leu & CCT & Pro & CAT & His & CGT & Arg \\
CTC & Leu & CCC & Pro & CAC & His & CGC & Arg \\
CTA & Leu & CCA & Pro & CAA & Gln & CGA & Arg \\
CTG & Leu & CCG & Pro & CAG & Gln & CGG & Arg \\
ATT & Ile & ACT & Thr & AAT & Asn & AGT & Ser \\
ATC & Ile & ACC & Thr & AAC & Asn & AGC & Ser \\
ATA & Ile & ACA & Thr & AAA & Lys & AGA & Arg \\
ATG & Met & ACG & Thr & AAG & Lys & AGG & Arg \\
GTT & Val & GCT & Ala & GAT & Asp & GGT & Gly \\
GTC & Val & GCC & Ala & GAC & Asp & GGC & Gly \\
GTA & Val & GCA & Ala & GAA & Glu & GGA & Gly \\
GTG & Val & GCG & Ala & GAG & Glu & GGG & Gly \\
\hline
\end{tabular}

Tabela 1.2: Código Genético

A tradução da seqüência de bases nitrogenadas para a seqüência de aminoácidos é feita por uma estrutura celular contida no citoplasma, chamada ribossomo. Os genes estão contidos no núcleo, e para transmitir a informação do núcleo existe uma molécula intermediária, denominada RNA mensageiro, ou mRNA, que é uma cópia do gene. Ela se move para o citoplasma, onde ocorre sua tradução em proteína. Esse fluxo de informação é chamado da dogma fundamental de biologia molecular e está ilustrado na figura 1.1. O processo real é muito mais complexo do que o descrito neste parágrafo. Não obstante, essa descrição simplificada presta-se somente a facilitar a compreenção do problema apresentado.

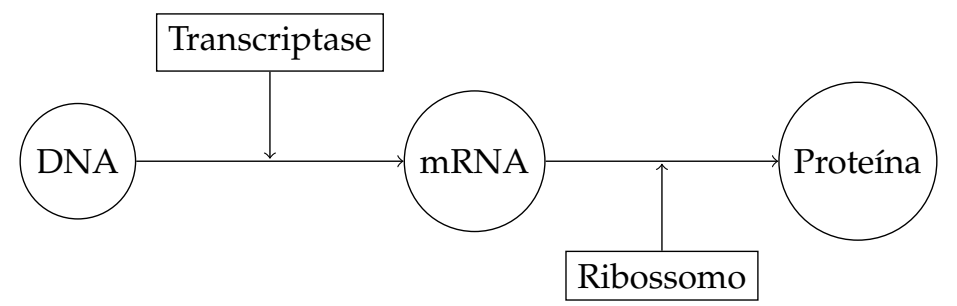

Figura 1.1: Fluxo de informação na célula do DNA até a proteína.

O mecanismo de transcrição do DNA para o mRNA existe não somente para superar a 
separação entre o cromossomo e o ribossomo, mas também para controlar a produção de proteínas. Existe um sistema complexo que determina qual gene será transcrito de acordo com as necessidades da célula. Existem proteínas específicas que interagem com o DNA para ativar a tradução de genes. Estes, por sua vez, produzem outras proteínas, e estas, ativam ou desativam outros genes. Esse processo se repete, estabelecendo um sistema dinâmico de alimentação e retroalimentação.

Elucidar esse sistema de interação de genes e proteínas é a chave para desvendar as causas genéticas dos processos biológicos, e pode permitir a compreensão de diversas doenças, abrindo caminho para o surgimento de novos remédios, terapias e métodos para diagnóticos.

\subsubsection{Rede complexa de genes}

Estima-se que o número de genes do ser humano seja da ordem de 30mil[89]. Cada gene pode gerar uma ou mais proteínas diferentes[18], que executam as mais diversas funções bioquímicas na célula. No projeto Gene Ontology[9] estão catalogados no momento 14.738 processos biológicos, 8.263 funções bioquímicas e 2.084 componentes celulares diferentes. Todas essas listas estão incompletas e os dados do Gene Ontology são atualizados diariamente com novas informações ou correções. Na figura 1.2 está demonstrado um dos milhares de processos biológicos que ocorrem nas células: o ciclo do ácido cítrico ${ }^{2}$, também conhecido como ciclo de Krebs, que integra o processo de respiração celular.

A complexidade do sistema celular seria intratável se não fosse o princípio reducionista de que toda informação biológica está contida nos genes, e de que o estudo dos genes possibilita extrair todas as informações necessárias à compreensão do funcionamento das células. Deste modo, mede-se a quantidade de mRNA nas células para tentar inferir quais genes estão atuando em cada momento. Espera-se que, medindo o mensageiro, seja possível compreender o funcionamento dos processos bioquímicos nas células. Nesta

\footnotetext{
${ }^{2}$ http://www.genome.jp/kegg/pathway/map/map00020.html
} 


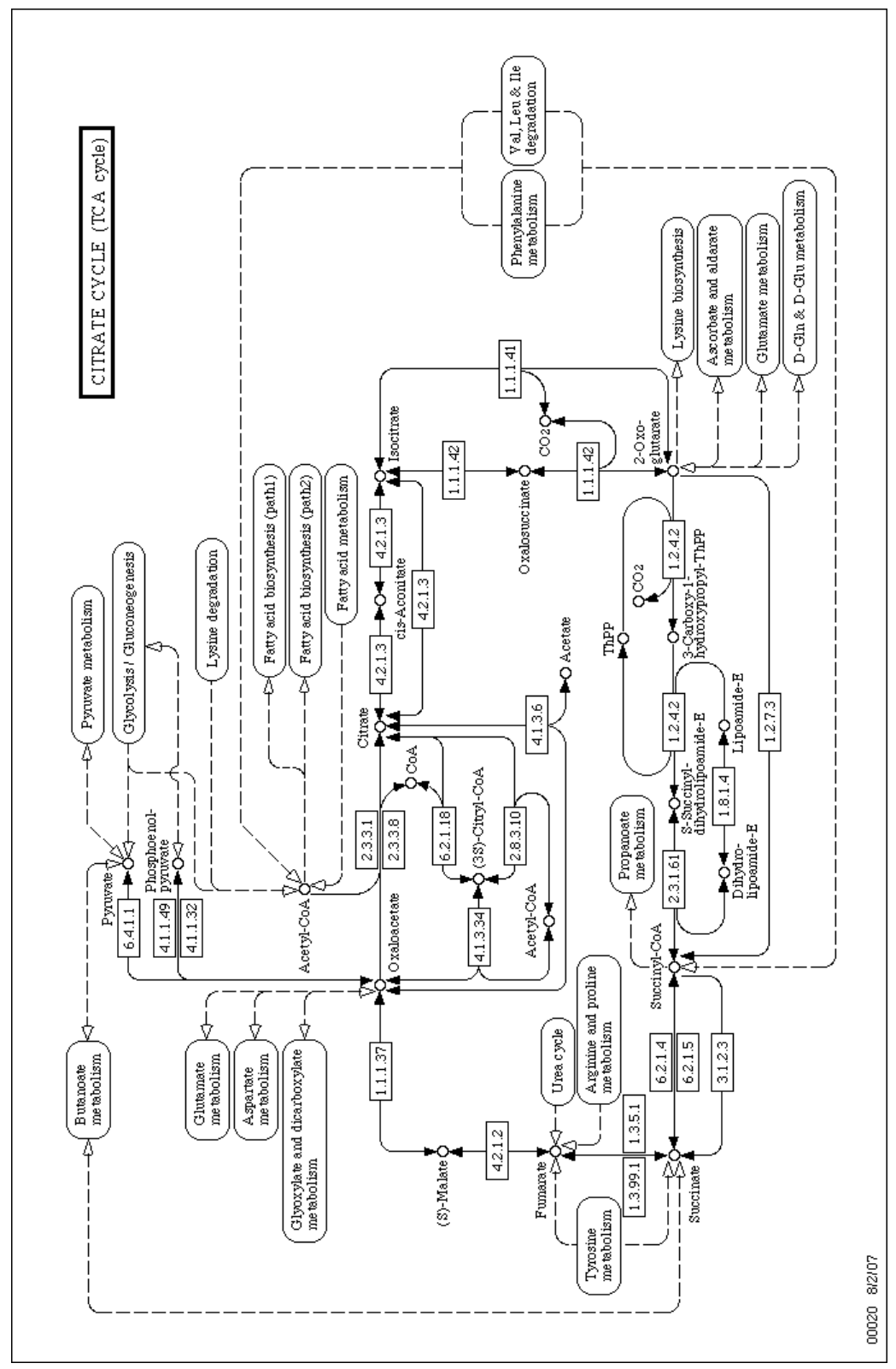

Figura 1.2: Via metabólica do ciclo do ácido cítrico. Fonte: KEGG. 
abordagem são construídas imagens estáticas do processo dinâmico que se desenvolve no interior da célula, mais ou menos como se tentássemos compreender o movimento a partir da observação de fotografias.

Além do estudo das células saudáveis, é de especial interesse o estudo das células que apresentam alguma doença, para descobrir qual processo biológico está diferente na célula problemática quando comparado ao mesmo processo na célula normal. Por isso são muito comuns os estudos que comparam tecidos normais e doentes.

\subsubsection{Medição do nível de mRNA}

A área de estudo da expressão gênica tem como objetivo final elucidar a rede de interações dos genes, medindo de maneira indireta a quantidade de mRNA em um tecido de interesse.

O que é chamado de nível de expressão gênica é a medição da quantidade de cada tipo mRNA na célula. Existem técnicas que permitem quantificar um mRNA específico, como o RT-PCR (Real Time Poly Chain Reaction)[52]. Porém, como existem milhares de tipos de moléculas, esta opção não é viável para o estudo global da expressão gênica. Por esse motivo, foram criadas técnicas para a quantificação simultânea de um grande número de mRNAs, as chamadas técnicas de grande volume (high-throughput).

Essas técnicas se dividem em duas famílias: as técnicas de hibridização e as técnicas de contagem de seqüências. A primeira família é formada pelas chamadas técnicas de microarray, as quais se baseiam na afinidade química de seqüências complementares de DNA. O experimento de microarray é realizado em uma placa de vidro, ou numa membrana de nylon, onde são fixadas milhares de sondas construídas a partir de seqüências conhecidas. O DNA de interesse é depositado sobre a lâmina, e os mRNAs migram para as sondas complementares a eles. A quantidade de mRNA em cada sonda é medida de maneira indireta, usualmente com uma substância emissora de luz vinculada às moléculas de mRNA depositadas. A quantidade de luz na posição de cada sonda é interpretada 
como a medida da expressão do gene representado por esta[61].

Na segunda família agrupam-se as técnicas de medição digital de expressão, que consistem no seqüênciamento e na contagem de trechos de cada mRNA. Essas técnicas consistem em seqüenciar um trecho da ponta do mRNA, chamado de tag. Elas variam em relação ao tamanho da tag e ao número total de tags obtidas em relação ao investimento de tempo e dinheiro, mas o princípio de contagem é o mesmo. Na primeira proposta de contagem de tags, foram seqüenciadas pouco mais de duzentas tags com centenas de bases[75]. Em seguida, surgiu a técnica de SAGE, que reduziu o tamanho das tags para somente dez bases, mas aumentou o total delas para dezenas de milhares. Outras variações em termos de comprimento da tag e detalhes da técnica foram desenvolvidas, como o Long SAGE. Mas a grande mudança para a contagem de tags encontra-se nos novos métodos de seqüênciamento, como o 454[44], o MPSS[17], o Illumina e o SOLiD[65], que permitem efetuar a contagem de milhões de tags em um único experimento.

Os métodos de microarray têm um custo inferior aos métodos de contagem, o que contribuiu para popularizá-los. No entanto, a medida indireta do nível de expressão insere incerteza ao resultado e dificulta a reprodução de experimentos[41]. Além disso, o microarray só consegue identificar a expressão das sondas previamente selecionadas para aquele experimento.

Por outro lado, a medida de contagem é uma informação mais concreta. Não depende do conhecimento prévio dos genes e, sobretudo, é uma medida muito mais simples de se modelar estatisticamente. Os custos dos métodos de contagem ainda são elevados, mas os novos seqüénciadores devem reduzi-los, pois a capacidade de seqüenciamento dos novos aparelhos é tão grande que permite a execução de mais de um experimento por vez[77]. 


\subsection{Objetivos}

O objetivo desta tese aperfeiçoar as técnicas de análise de bibliotecas digitais de expressão gênica através de melhorias na modelagem estatística das freqüências observadas. Mais específicamente pretendemos:

- Desenvolver e implementar testes de significância para identificar tags diferencialmente expressas em conjuntos de bibliotecas digitais de expressão gênica, que não dependam de resultados assintóticos, e portanto, possam ser aplicados para todas as tags independentemente do seu nível de expressão.

- Criar uma aplicação que permita o uso da distância de Aitchison em análises de agrupamento baseadas em distância, como agrupamento hierárquico, k-médias e kmedóides. Assim como analisar o desempenho desta medida de distância em dados reais.

A principal contribuição deste trabalho para a bioinformática é agregar, à área de análise de expressão gênica, métodos desenvolvidos para problemas completamente diferentes. Essa transposição de conhecimento é possível, desde que acompanhada de uma análise cuidadosa da natureza dos dados que estão sendo estudados. 


\subsection{Convenções Utilizadas}

1. $\mathbb{1}_{D}$ representa um vetor dimensão $\mathrm{D}$ e elementos iguais a um, quando não houver dúvidas, ou quando a dimensão do vetor não for relevante para a discussão, o subscrito D será omitido.

2. Vetores serão sempre representados por letras em negrito, x. Os componentes do vetor são escritos com a mesma letra do vetor com a posição indicada no subescrito. Por exemplo, $x_{1}$ é o primeiro componente do vetor $\mathbf{x}$. Se o vetor já tiver um subescrito, a componente é identificada com a posição antes do subescrito, por exemplo, a primeira componente do vetor $\mathbf{x}_{j}$ é indicada por $\mathbf{x}_{1 j}$.

3. M matrizes serão representadas por letras maiúsculas, no estilo blackboard.

4. O termo "tag" será utilizado no sentido amplo, para designar o marcador de gene, podendo designar assinaturas de MPSS ou contigs de EST. Alguns autores sugerem a tradução de tag como etiqueta, porém esta tradução não é usualmente utilizada na área de Bioinformática e Biologia Molecular.

5. O produto escalar dos vetores a e b será indicado simplesmente como ab. A diferença termo a termo entre dois vetores será indicada por $\mathbf{a}-\mathbf{b}$, e a diferença entre um vetor e um escalar $\mathbf{a}-b=\left[a_{1}-b, \cdots, a_{k}-b\right]$. A norma de um vetor é indicada por $\|\mathbf{a}\|=\sqrt{\mathbf{a a}}$.

6. $\mathbb{P}(A)$ indica a probabilidade do evento $\mathrm{A}$.

7. A notação $f(x) \propto g(x)$ indica que $f$ é proporcional a $g$, ou seja, $f(x)=c g(x), \forall x$; onde c é uma constante normalizadora que não depende de $x$.

8. Para um conjunto $C$, a sua cardinalidade é indicada por $|C|$. 


\section{Capítulo 2}

\section{Modelagem Probabilística da Contagem}

\section{de Transcritos}

Uma modelagem probabilística simples é um diferencial muito importante entre as técnicas de contagem e as técnicas de hibridização. Esta modelagem é o cerne das técnicas de análise que serão mostradas nos próximos capítulos.

Neste capítulo, serão apresentados os dados de contagem. O Modelo Multinomial será proposto como modelo probabilístico para esses dados, e serão discutidas algumas propriedades matemáticas do modelo.

\subsection{Os dados}

Diversos conjuntos de dados de contagem de transcritos estão disponíveis publicamente no projeto GEO(Gene Expression Omnibus) ${ }^{1}$ e no projeto SAGE Genie[59] ${ }^{2}$. Por exemplo, o código GSE667 permite acessar o conjunto de dados feitos por Pu-Ting Xu[96]. Trata-se de um conjunto formado por quatro bibliotecas de SAGE e duas de Long SAGE ${ }^{3}$ obtidas a partir de tecidos do hipocampo do cérebro. Na tabela 2.1, estão os totais para as bibliotecas

\footnotetext{
${ }^{1}$ http://www.ncbi.nlm.nih.gov/geo/

${ }^{2}$ http://cgap.nci.nih.gov/SAGE/SAGELibraryFinder

${ }^{3}$ O Long SAGE é uma variação do SAGE onde as tags possuem 17 em vez de 10 bases
} 
de SAGE e Long SAGE.

\begin{tabular}{lrrrr|rr}
\multicolumn{5}{c|}{ SAGE } & \multicolumn{2}{c}{ Long SAGE } \\
\hline \hline Biblioteca & AD 3/3 & N 3/3 & AD 3/4 & AD 4/4 & N 3/3 & AD 3/3 \\
\hline$N_{j}$ & 78.134 & 70.470 & 72.095 & 67.984 & 76.030 & 81.208 \\
$M_{n z}$ & 25.141 & 23.128 & 24.663 & 22.167 & 31.516 & 35.334 \\
\hline$M$ & \multicolumn{3}{c}{60.408} & & \multicolumn{2}{c}{56.853} \\
\hline
\end{tabular}

Tabela 2.1: Resumo de alguns conjuntos de dados de SAGE e Long SAGE de doença de Alzheimer. $N_{j}$ representa o total de tags contadas; $M_{n z}$ o número de tags com contagem diferente de zero; e $M$ indica o número total de tags distintas em cada grupo de bibliotecas. O nome das bibliotecas indicam o diagnóstico do paciente, $\mathrm{N}$ para normal e AD para Doença de Alzheimer, seguido do genótipo do gene APOE.

Na tabela 2.3, tem-se um pequeno exemplo de uma matriz com a contagem de tags para quatro bibliotecas, das quais três são resultantes de tecidos coletados de doentes com doença de Alzheimer, e uma de um paciente normal. Na tabela, estão indicados os valores de $x_{i j}$ e de $y_{i}=\sum_{j=1}^{4} x_{i j}$. As linhas estão ordenadas pelo valor de $y_{i}$. Nota-se uma grande variação na contagem total por tag, os valores $y_{i}$ estão no intervalo de 1 a 4718 . No entanto as contagens baixas são muito mais numerosas que as contagens altas, conforme se pode observar na tabela 2.2, onde estão os quartis de y. Nota-se que a contagem da maioria das tags não passa de 1 .

\begin{tabular}{ll|lr} 
Mínimo & 1,0 & Média & 4,8 \\
$1^{\circ}$ Quartil & 1,0 & $3^{\circ}$ Quartil. & 2,0 \\
Mediana & 1,0 & Máximo & $4.718,0$
\end{tabular}

Tabela 2.2: Quartis, média e mediana da variável y para os dados de doença de Alzheimer.

Existem duas explicações para o grande número de tags com contagem unitária. Em primeiro lugar, sabe-se que a maioria dos genes possui uma expressão baixa e que poucos genes têm uma expressão muito elevada. O segundo motivo é que o processo de identificação de tags comete erros[85]. Muitas tags unitárias podem, na verdade, ser outra tag, cujo seqüenciamento contém algum erro. Diversos métodos foram propostos para tentar corrigir o erro de contagem causado pela identificação errada[15, 7, 27]. No entanto, é muito difícil separar as tags defeituosas das tags normais. Uma possibilidade é remover as tags que não mapeiam no genoma, porém, para as tags de SAGE de 10 bases, 
não é possível garantir que o mapeamento não ocorra por acaso. Novas técnicas de contagem utilizam tags mais longas, com 27 ou 35 bases, e para essas técnicas a abordagem de mapeamento deve ser mais eficiente.

Na aplicação dos métodos propostos, optou-se por eliminar as tags com contagem muito baixa. Uma regra prática é normalizar as contagens pelo total da biblioteca menor, e desconsiderar as tags cuja contagem normalizada seja inferior ao número de bibliotecas.

\begin{tabular}{llrrrrr} 
& TAG & AD $3 / 3$ & N 3/3 & AD 3/4 & AD $4 / 4$ & \\
\hline \hline $\mathrm{i}$ & & $\mathbf{x}_{1}$ & $\mathbf{x}_{2}$ & $\mathbf{x}_{3}$ & $\mathbf{x}_{4}$ & $y$ \\
1 & GTGAAACCCC & 934 & 929 & 1427 & 1428 & 4718 \\
2 & CCACTGCACT & 803 & 731 & 1216 & 1493 & 4243 \\
3 & CAAGCATCCC & 1089 & 1091 & 1056 & 873 & 4109 \\
4 & CACCTAATTG & 1098 & 962 & 998 & 776 & 3834 \\
5 & CCTGTAATCC & 670 & 683 & 1161 & 1093 & 3607 \\
6 & CCCATCGTCC & 720 & 661 & 1001 & 888 & 3270 \\
7 & CTAAGACTTC & 874 & 853 & 837 & 381 & 2945 \\
8 & GTGAAACCCT & 639 & 558 & 810 & 778 & 2785 \\
9 & ACCCTTGGCC & 507 & 481 & 387 & 151 & 1526 \\
10 & AAAACATTCT & 306 & 265 & 501 & 431 & 1503 \\
11 & ACTAACACCC & 459 & 483 & 417 & 143 & 1502 \\
12 & TAACCAAGAG & 0 & 0 & 1466 & 0 & 1466 \\
$\vdots$ & $\vdots$ & $\vdots$ & $\vdots$ & $\vdots$ & $\vdots$ & $\vdots$ \\
483 & AACCCGGAAG & 8 & 12 & 21 & 16 & 57 \\
484 & AGACATTGTA & 29 & 20 & 2 & 6 & 57 \\
485 & GAAATGATGA & 24 & 15 & 11 & 7 & 57 \\
486 & CGGCTGCCCA & 28 & 16 & 3 & 10 & 57 \\
487 & CCCCGCAGCT & 23 & 29 & 1 & 4 & 57 \\
488 & TAACCAAACA & 13 & 12 & 13 & 19 & 57 \\
489 & GAACACATCC & 24 & 9 & 9 & 15 & 57 \\
$\vdots$ & $\vdots$ & $\vdots$ & $\vdots$ & $\vdots$ & $\vdots$ & $\vdots$ \\
60404 & CTGCTTGGGA & 0 & 0 & 1 & 0 & 1 \\
60405 & CTGCTTGAGG & 0 & 0 & 1 & 0 & 1 \\
60406 & CTGCTTTTTA & 0 & 1 & 0 & 0 & 1 \\
60407 & CTGCTTTGGT & 0 & 0 & 1 & 0 & 1 \\
60408 & CTGCTTTCAT & 1 & 0 & 0 & 0 & 1 \\
\hline
\end{tabular}

Tabela 2.3: Exemplo de matriz de dados com as contagens para as bibliotecas de SAGE. O nome das bibliotecas indicam o diagnóstico do paciente, N para normal e AD para Doença de Alzheimer, seguido do genótipo do gene APOE. 


\subsection{Modelo Multinomial}

Supondo que cada tag tenha uma probabilidade $p_{i j}$ de ser contada, e que existam $M$ tags distintas, é razoável supor a distribuição mulinomial para o vetor $\mathbf{X}_{j}$ com todas as contagens para um total de $N_{j}$ tags em cada biblioteca $j$ (eq. 2.1).

$$
f\left(\mathbf{X}_{j}=\mathbf{x} \mid \mathbf{P}=\mathbf{p}\right)=\frac{N !}{x_{1} ! \cdots x_{M} !} p_{1}^{x_{1}} \cdots p_{M}^{x_{M}}
$$

Deste modelo, segue que as contagens são condicionalmente indepedentes, dado o valor de $\mathbf{p}$ :

$$
X_{1 j} \Perp X_{2 j} \Perp \cdots \Perp X_{M j} \mid \mathbf{p}_{j},
$$

ou seja, se conhecermos o valor de $\mathbf{p}_{j}$, o valor da variável $X_{a j}$ não nos traz nenhuma informação adicional sobre o valor de $X_{b j}$, para quaisquer a e $b$, tal que $a \neq b$.

Segue também que a distribuição da contagem de cada tag é uma binomial com parâmetros $p_{i j}$ e $N_{j}$ (eq. 2.2).

$$
f\left(X_{i j}=x \mid p_{i j}, N_{j}\right)=\left(\begin{array}{c}
N_{j} \\
x
\end{array}\right) p_{i j}{ }^{x}\left(1-p_{i j}\right)^{N_{j}-x}
$$

\subsubsection{Distribuição a posteriori do parâmetro $P$}

Quando a função de probabilidade $f(\mathbf{X} \mid \mathbf{P})$ é considerada como uma função de $\mathbf{P}$ para um valor fixo $\mathbf{X}$, ela é chamada de função de verossimilhança. Essa função é relevante devido ao teorema de Bayes:

$$
\xi(\mathbf{P} \mid \mathbf{X})=\frac{f(\mathbf{X} \mid \mathbf{P}) \xi(\mathbf{P})}{g(\mathbf{X})}
$$

Esse teorema é de grande importância para a estatística, pois permite que se calcule a probabilidade do parâmetro após a observação dos dados $\xi(\mathbf{P} \mid \mathbf{X})$, a chamada densidade a posteriori, que é o produto da verossimilhança $f(\mathbf{X} \mid P)$ pela densidade a priori do 
parâmetro $\xi(\mathbf{P})$. A função $g(\mathbf{X})$ do denominador não depende de $\mathbf{P}$. Por isso, muitas vezes, a distribuição a posteriori é escrita na forma proporcional (eq. 2.4).

$$
\xi(\mathbf{P} \mid \mathbf{X}) \propto f(\mathbf{X} \mid \mathbf{P}) \xi(\mathbf{P})
$$

\subsubsection{Priori Conjugada Natural}

Para algumas distribuições, é matematicamente mais simples escolher uma priori com uma determinada forma funcional. No caso da distribuição binomial, a conjugada natural é a distribuição Beta (eq. 2.5), onde $B(\alpha, \beta)$ é a função Beta (eq. 2.6). Aplicando o teorema de Bayes (eq. 2.4), vê-se que a posteriori é, a menos da constante normalizadora, uma densidade Beta, mas com parâmetros $x+\alpha$ e $N-x+\beta$ (eq. 2.7).

$$
\begin{aligned}
\xi(p) & =\frac{1}{\mathrm{~B}(\alpha, \beta)} p^{\alpha-1}(1-p)^{\beta-1} \\
\mathrm{~B}(\alpha, \beta) & =\frac{\Gamma(\alpha+\beta)}{\Gamma(\alpha) \Gamma(\beta)} \\
\xi(p \mid x) & \propto p^{x+\alpha-1}(1-p)^{N-x+\beta-1}
\end{aligned}
$$

De maneira similar, a conjugada da multinomial é a distribuição de Dirichlet (eq. 2.8), cujos parâmetros da posteriori são $x_{1}+\alpha_{1}, \cdots, x_{n}+\alpha_{n}$.

$$
\begin{aligned}
\xi\left(p_{1}, \ldots, p_{n}\right) & =\frac{1}{\mathrm{~B}\left(\alpha_{1}, \ldots, \alpha_{n}\right)} p_{1}^{\alpha_{1}-1} \cdots p_{n}^{\alpha_{n}-1} \\
\mathrm{~B}\left(\alpha_{1}, \cdots, \alpha_{n}\right) & =\frac{\Gamma\left(\alpha_{1}+\cdots+\alpha_{n}\right)}{\Gamma\left(\alpha_{1}\right) \cdots \Gamma\left(\alpha_{n}\right)}
\end{aligned}
$$

O uso da conjugada natural permite menos liberdade ao modelar a priori, pois a forma funcional da distribuição é fixada, e somente os parâmetros podem ser escolhidos. Mas, 
em diversos problemas, essa opção é suficiente para representar o conhecimento a priori sobre o parâmetro, ou seja, o conhecimento antes da observação dos dados. Por exemplo, o desconhecimento sobre o valor do parâmetro pode ser representado por uma Dirichlet $\operatorname{com} \alpha_{i}=1$, pois neste caso a priori é uma uniforme.

\subsection{Poisson}

Quando $\mathrm{N}$ for grande e $\mathrm{p}$ for pequeno, a distribuição binomial pode ser aproximada da seguinte forma: para $x=1,2,3, \cdots$ se escreve o valor de $\mathbb{P}(X=x \mid n, p)$ :

$$
\mathbb{P}(X=x \mid N, p)=\frac{N(N-1) \cdots(N-x+1)}{x !} p^{x}(1-p)^{N-x}
$$

Seja $\lambda=N p$, portanto $f(x \mid N, p)$ pode ser reescrito como:

$$
\mathbb{P}(X=x \mid N, p)=\frac{\lambda^{x}}{x !} \frac{N}{N} \frac{N-1}{N} \cdots \frac{N-x+1}{N}\left(1-\frac{\lambda}{N}\right)^{N}\left(1-\frac{\lambda}{N}\right)^{-x}
$$

Fazendo $N \rightarrow \infty$ e $p \rightarrow 0$, mas de forma a manter o valor de $\lambda$ constante, temos que:

$$
\lim _{N \rightarrow \infty} \frac{N}{N} \frac{N-1}{N} \cdots \frac{N-x+1}{N}\left(1-\frac{\lambda}{N}\right)^{-x}=1
$$

E do cálculo temos que:

$$
\lim _{N \rightarrow \infty}\left(1-\frac{\lambda}{N}\right)^{N}=e^{-\lambda}
$$

Segue da equação 2.11 que, para todo x positivo:

$$
\mathbb{P}(X=x \mid N, p) \rightarrow \frac{e^{-\lambda} \lambda^{x}}{x !}
$$

Finalmente, para $x=0$ 


$$
\mathbb{P}(X=x \mid N, p)=(1-p)^{N}=\left(1-\frac{\lambda}{n}\right)^{N} \rightarrow e^{-\lambda}
$$

A equação 2.14 é conhecida como distribuição de Poisson, e quando $\mathrm{N}$ é grande e p é pequeno, ela se aproxima da distribuição Binomial.

No conjunto de dados do exemplo, os valores de $\frac{x_{i j}}{N_{j}}$ variam entre 0,021 e 1, 28 $\times 10^{-5}$, e $N_{j}$ é da ordem de 70 mil. Como as bibliotecas tipicamente possuem valores como estes, ou mais extremos, é razoável aproximar $X_{i j}$ pela distribuição de Poisson (eq. 2.16). Essa aproximação é amplamente utilizada em estudos de contagem de genes[10, 20, 102, 15, 101].

$$
\mathbb{P}\left(X_{i j}=x \mid N_{j}, p_{i j}\right)=\frac{e^{-\left(N_{j} p_{i j}\right)}\left(N_{j} p_{i j}\right)^{x}}{x !}
$$

\subsubsection{Probabilidade conjunta de diversas Poissons}

Nesta seção, será discutida a probabilidade conjunta de diversas variáveis aleatórias com

distribuição de Poisson. Primeiramente será mostrado o caso com somente duas variáveis, e em seguida, o resultado será estendido para $k$ variáveis.

Sejam $X_{1}$ e $X_{2}$ duas variáveis aleatórias, com distribuição de Poisson com parâmetros $\lambda_{1} \in(0, \infty)$ e $\lambda_{2} \in(0, \infty)$, e densidade conjunta dada pela eq. 2.17.

$$
\mathbb{P}\left(X_{1}=x_{1}, X_{2}=x_{2}\right)=\frac{e^{-\lambda_{1}} \lambda_{1}^{x_{1}}}{x_{1} !} \frac{e^{-\lambda_{2}} \lambda_{2}^{x_{2}}}{x_{2} !}
$$

Definem-se os novos parâmetros $\theta=\lambda_{1}+\lambda_{2}$ e $\pi=\frac{\lambda_{1}}{\lambda_{1}+\lambda_{2}}$ com intervalos de variação independentes $\Theta \in(0, \infty)$ e $\pi \in(0,1)$. Substituindo $\lambda_{1}=\theta \pi$ e $\lambda_{2}=\theta(1-\pi)$ em 2.17, tem-se, para $y=x_{1}+x_{2}$, a seguinte equação:

$$
\mathbb{P}\left(X_{1}=x_{1}, X_{2}=x_{2}\right)=e^{-\theta} \theta^{x_{1}+x_{2}} \frac{\pi^{x_{1}}(1-\pi)^{x_{2}}}{x_{1} ! x_{2} !}=\underbrace{\frac{e^{-\theta} \theta^{y}}{y !}}_{\text {Poisson }} \underbrace{\frac{y !}{x_{1} ! x_{2} !} \pi^{x_{1}}(1-\pi)^{x_{2}}}_{\text {Binomial }}
$$


Portanto, é sempre possível escrever a distribuição conjunta como o produto das distribuições de $X_{1}$ e $Y=X_{1}+X_{2}$, que são respectivamente uma Binomial com parâmetros $\pi$ e $y$, e uma Poisson com parâmetro $\theta: \mathbb{P}\left(X_{1}, X_{2}\right)=\mathbb{P}\left(X_{1}, Y\right)=\operatorname{Bin}(x \mid y, \pi)$ Poisson $(y \mid \theta)$

Generaliza-se o resultado anterior para $k$ variáveis $X_{i}$, com distribuição Poisson e parâmetros $\lambda_{1}, \lambda_{2}, \cdots, \lambda_{k}$, definindo $\theta=\lambda_{1}+\cdots+\lambda_{k}$ e $\pi_{i}=\frac{\lambda_{i}}{\theta}$. A probabilidade conjunta de $\mathbf{X}$ (eq. 2.19) é reparametrizada com $\lambda_{i}=\theta \pi_{i}$ (eq 2.20), e, de maneira similar, a densidade conjunta é fatorada no produto de uma Multinomial com parâmetros $\Pi=\left(\pi_{1}, \cdots, \pi_{k}\right)$ por uma Poisson com parâmetro $\theta$.

$$
\begin{gathered}
\mathbb{P}\left(\mathbf{X}=\left(x_{1}, \cdots, x_{k}\right)\right)=\frac{\lambda_{1}^{x_{1}} \cdots \lambda_{k}^{x_{k}}}{x_{1} ! \cdots x_{k} !} e^{\lambda_{1}+\cdots+\lambda_{k}} \\
\mathbb{P}\left(X_{1}=x_{1}, \cdots, X_{k}=x_{k}, Y=y\right)=\frac{e^{-\theta} \theta^{y}}{y !} \frac{y !}{x_{1} ! \cdots x_{k} !} \pi_{1}^{x_{1}} \cdots \pi_{k}^{x_{k}}
\end{gathered}
$$




\section{Capítulo 3}

\section{Kemp: Teste Estatístico Clássico para a Comparação da expressão de Tags}

O estudo da expressão gênica leva à seguinte questão: O nível de expressão das tags muda de biblioteca para biblioteca? Considere, por exemplo, duas bibliotecas. Uma é gerada a partir de um tecido saudável, e a outra por um tecido tumoral. Se o nível de expressão de uma tag for diferente entre as duas bibliotecas, tem-se uma indicação de que a tag pode estar envolvida no processo tumoral.

Para avaliar se uma determinada tag é expressa diferentemente em um conjunto de bibliotecas utilizaremos testes de significância. Um teste de significância é uma medida numérica da coerência dos dados observados em relação a uma hipótese definida por uma distribuição de probabilidade[56]. Um exemplo de teste de significância muito utilizado na bioinformática é o e-value do blast[8], que compara o score do alinhamento obtido em relação à hipótese nula de que este alinhamento representa homologia entre as seqüências analisadas.

Neste capítulo será mostrado o cálculo de um índice de significância exato, utilizando como hipótese nula a não diferenciação das tags. Ou seja, supondo que não exista diferença entre os níveis de expressão, calcula-se o quão incoerente é a observação feita 
em relação a esta hipótese.

Por exato queremos dizer que o índice calculado não depende de nenhum resultado assintotico, e portanto pode ser aplicado tanto para tags com baixa expressão, quanto para tags com alta expressão.

\subsection{Teste de Significância}

Segundo Kempthorne[55] o nível de significância é uma medida da consistência da observação $\mathbf{X}$ em relação a uma hipótese $H_{0}$. Uma hipótese é uma afirmação sobre o valor de um parâmetro desconhecido $p$ contido em um espaço paramétrico $\Theta$. Comumente, as hipóteses são consideradas em pares. A hipótese contra a qual se calcula a significância é chamada de hipótese nula $H_{0}$, e a outra, de hipótese alternativa $H_{1}$. Uma hipótese $p=p_{0}$, que contém um único valor é dita simples, caso contrário, é dita composta.

O primeiro passo para construir o teste de significância para diferenciação de tags é especificar, de maneira mais precisa, o parâmetro na qual será executado o teste. Esse parâmetro é o vetor $\mathbf{P}_{i}=\left[p_{i 1}, \cdots, p_{i k}\right]$, com o nível de expressão da tag i, nos $k$ tecidos estudados. Note que esta se considerando os valores de $p_{i j}$ para um mesmo valor de $i$, e portanto pode-se, para simplificar a notação, omitir o índice $i$, portanto $\mathbf{P}=\left[p_{1}, \cdots, p_{k}\right]$. Como os valores de $\sum_{i=1}^{k} p_{i j}$ não precisa ser igual à 1 , o espaço paramétrico é definido no espaço dado por 3.1, ou seja, o hipercubo de lado unitário no quadrante positivo.

$$
\Theta=\left\{\left[p_{1}, \ldots, p_{k}\right] \in \mathbb{R}_{+} \mid p_{1} \leq 1 \wedge \cdots \wedge p_{k} \leq 1\right\}
$$

Em seguida, define-se a hipótese nula de não-diferenciação: $H_{0}: p_{1}=p_{2}=\cdots=$ $p_{k-1}=p_{k}$. Conseqüentemente, $H_{1}$ fica definida como a não igualdade das proporções. Graficamente, $H_{0}$ é uma linha, e $H_{1}$ é o restante do espaço paramétrico. Na figura 3.1, está ilustrado $H_{0}$ e $H_{1}$ para $\mathrm{k}=3$ e somente $p_{1}$ e $p_{2}$ são mostrados pois $p_{3}=1-p_{1}-p_{2}$ esta implícito. A hipótese nula é a reta $p_{1}=p_{2}$. 
A definição da hipótese nula tem uma implicação muito importante para o teste, pois testa-se a igualdade de expressão em todos os tecidos. No caso em que $H_{1}$ é verdadeiro, pode-se afirmar que a expressão não é igual, mas não se pode afirmar qual dos tecidos, ou grupo de tecidos, tem a expressão diferente dos outros.

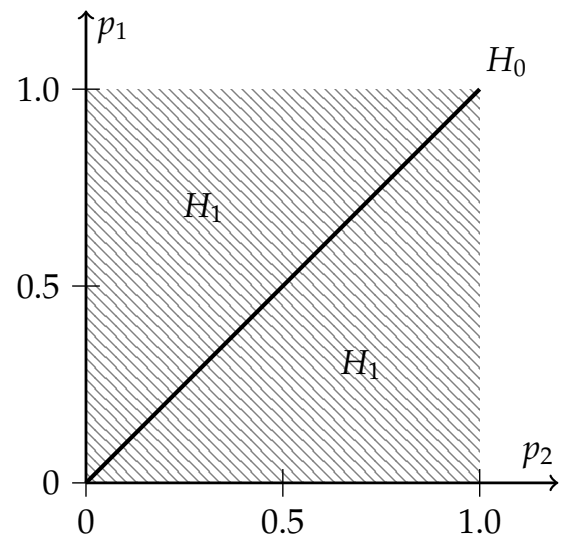

Figura 3.1: Ilustração da hipótese nula $H_{0}$ (linha escura), e da hipótese alternativa $H_{1}$ (região hachurada), para $\mathrm{k}=3$.

A distribuição de cada contagem é uma Binomial (seção 2.2) que pode ser aproximada por uma Poisson com parâmetro $\lambda_{j}=N_{j} p_{j}$ (seção 2.3). A distribuição conjunta é o produto das Poissons. Porém, não existe um procedimento exato para testar a homogenieidade de Poissons.

No entanto, se a fatoração apresentada na seção 2.3.1 for utilizada, com a reparametrização $\theta=N_{1} p_{1}+\cdots+N_{k} p_{k}$ e $\pi_{j}=\frac{N_{j} p_{j}}{\theta}$, tem-se que a verossimilhança

$$
\mathbb{P}(\mathbf{X} \mid \Pi, \theta)=\operatorname{Multinomial}(\mathbf{X} \mid \Pi, y) \operatorname{Poisson}(\mathbf{y} \mid \theta)
$$

depende dos parâmetros $\Pi$ e $\theta$. Mas, como os parâmetros $\pi_{i}$ têm variação independente de $\theta$, e a hipótese nula depende somente de $\Pi$, pode-se classificar $\theta$ como parâmetro inconveniente (nuisance parameter)[14], e tomar somente a verossimilhança parcial [30] condicionada em y (eq. 3.2). O condicionamento é muito importante, pois ao fixar o valor de y limita-se o espaço amostral, que de outra forma seria infinito. Essa limitação facilita 
o cálculo do nível de significância a ser explicado na próxima seção.

$$
\mathbb{P}\left[\mathbf{X}=\left(x_{1}, \cdots, x_{k}\right) \mid \Pi, y\right]=\frac{y !}{x_{1} ! \cdots x_{k} !} \prod_{i=1}^{k} \pi_{i}^{x_{i}}
$$

Além disso, sobre a hipótese nula $p_{1}=\cdots=p_{k}=p$, tem-se que $\pi_{j}=\frac{N_{j} p}{N_{1} p+\cdots+N_{k} p}=\frac{N_{j}}{N}$ onde $N=N_{1}+\cdots+N_{k}$. Portanto, a hipótese nula sobre os parâmetros $\pi_{j}$ é uma hipótese simples (eq. 3.3). Na figura 3.2, estão ilustradas $H_{0}^{\prime}$ e $H_{1}^{\prime}$.

$$
H_{0}^{\prime}:\left(\pi_{1}, \cdots, \pi_{k}\right)=\left(\frac{N_{1}}{N}, \cdots, \frac{N_{k}}{N}\right)
$$

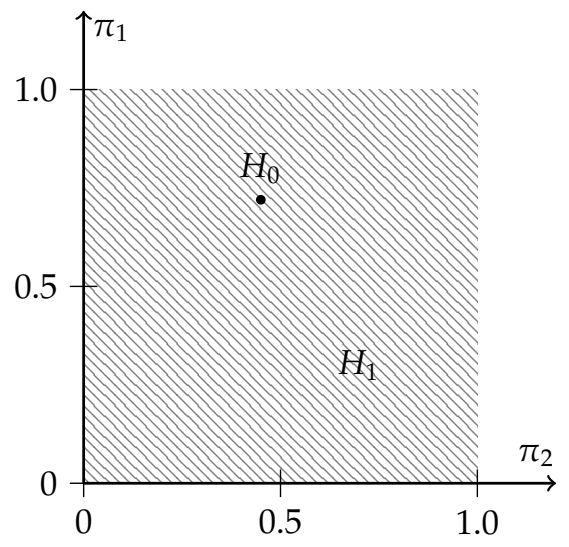

Figura 3.2: Ilustração da nova formulação da hipótese nula $H_{0}^{\prime}$ (ponto preto), e da hipótese alternativa $H_{1}^{\prime}$ (região hachurada), para $\mathrm{k}=3$.

\subsubsection{Cálculo do Nível de Significância}

Um nível de significância muito utilizado é o $p$-valor, definido por Cox como:

Definição 1. Um teste estatístico é obtido pela escolha de uma estatística $t(w)$, com $\mathrm{T}=t(w)$ sendo a variável aleatória correspondente. Portanto, um teste de significância da hipótese nula $\mathrm{H}_{0}$ é a obtenção do nível de significância para um valor observado $x$, ou seja, pv $(x)=\mathbb{P}[\mathrm{T} \leq t(x)][31]$.

Por essa definição, $\mathrm{T}$ é o critério que ordena os pontos do espaço amostral e define a região com valores de $T$ mais extremos que o ponto observado $X$. A razão de 
verossimilhança

$$
\frac{\mathrm{L}\left(\mathbf{X} \mid H_{0}^{\prime}\right)}{\mathrm{L}\left(\mathbf{X} \mid H_{1}^{\prime}\right)}
$$

é a escolha para T que ordena os pontos amostrais $x$ de modo que $t(x)$ aumenta conforme $x$ se torna mais favorável para a hipótese nula.

Como a hipótese nula é simples, basta calcular o valor da verossimilhança com o valor de $\left(\pi_{1}, \cdots, \pi_{k}\right)$ dado por $H_{0}^{\prime}$. Porém, para calcular o valor de $\mathrm{L}\left(\mathbf{X} \mid H_{1}^{\prime}\right)$, é preciso escolher uma projeção do espaço paramétrico. Neyman e Pearson utilizam o máximo da verossimilhança como projeção, já Dempster[39] sugere o uso da média. Escolhemos utilizar o máximo de $L_{1}$, pois esta é a escolha mais favorável para a hipótese alternativa, além de ser computacionalmente mais simples de calcular.

$\mathrm{O}$ valor máximo de $\mathrm{L}\left(\mathbf{X} \mid H_{1}\right)$ ocorre quando $\Pi_{1}=\left(\frac{x_{1}}{y}, \cdots, \frac{x_{k}}{y}\right)$. Ilustrativamente, a dedução deste fato para $k=3$ esta na figura 3.3. Relembrando que hipótese nula é $\Pi_{0}=\left(\frac{N_{1}}{N}, \cdots, \frac{N_{k}}{N}\right)$, tem-se que:

$$
\mathrm{T}=R(\mathbf{X})=\frac{\mathrm{L}\left(H_{0}\right)}{\max \mathrm{L}\left(H_{1}\right)}=\frac{\prod_{i=1}^{k}\left(\frac{N_{i}}{N}\right)^{x_{i}}}{\prod_{i=1}^{k}\left(\frac{x_{i}}{y}\right)^{x_{i}}} .
$$

Rearranjando os produtórios da equação 3.4:

$$
R(\mathbf{X})=\left(\frac{y}{N}\right)^{y} \prod_{j=1}^{k}\left(\frac{N_{j}}{x_{j}}\right)^{x_{j}} .
$$

Pela equação 3.5 e pela definição 1 , o p-valor é calculado pela expressão:

$$
\mathrm{pv}=\mathbb{P}[R(w) \leq R(X)]=\sum_{\mathcal{T}(\mathbf{X})} \frac{y !}{\prod_{j=1}^{k} w_{j} !} \prod_{j=1}^{k}\left(\frac{N_{j}}{N}\right)^{w_{j}}
$$

Sendo que $\mathcal{T}$ é a a calda da distribuição, definida por:

$$
\mathcal{T}(\mathbf{X})=\left\{\mathbf{W}=\left(w_{1}, \cdots, w_{k}\right) \in \mathbb{N}_{+}^{k} \mid \sum_{j=1}^{k} w_{j}=\sum_{j=1}^{k} x_{j} \wedge R(\mathbf{W}) \leq R(\mathbf{X})\right\}
$$


Fixando os valores de $\mathbf{x}$ e $y$ e calculando as derivadas parciais em relação a $\Pi$ :

$$
\begin{aligned}
& L\left(\pi_{1}, \pi_{2}, 1-\pi_{1}-\pi_{2}\right) \propto \pi_{1}^{x_{1}} \pi_{2}^{x_{2}}\left(1-\pi_{1}-\pi_{2}\right)^{y-x_{1}-x_{2}} \\
& \log [L] \propto x_{1} \log \left[\pi_{1}\right] x_{1} \log \left[\pi_{2}\right]+ \\
& \left(y-x_{1}-x_{2}\right) \log \left[1-\pi_{1}-\pi_{2}\right] \\
& {\left[\frac{d L}{d \pi_{1}}, \frac{d L}{d \pi_{2}}\right]=\left[\frac{x_{1}}{p_{1}}, \frac{x_{2}}{p_{2}}\right]-\frac{y-x_{1}-x_{2}}{1-\pi_{1}-\pi_{2}} \mathbb{1}}
\end{aligned}
$$

Igualando 3.10 a [0,0], resolvendo o sistema para $\pi_{1}$ e $\pi_{2}$ e lembrando que $\pi_{3}=1-\pi_{1}-\pi_{2}$, tem-se que:

$$
\left[\hat{\pi}_{1}, \hat{\pi}_{2}, \hat{\pi}_{3}\right]=\left[\frac{x_{1}}{y}, \frac{x_{2}}{y}, \frac{x_{3}}{y}\right]
$$

Figura 3.3: Dedução do valores de $\hat{\pi}_{1}, \hat{\pi}_{2}, \hat{\pi}_{3}$ que maximizam a multinomial de 3 classes.

A construção do método para o cálculo exato do p-valor que apresentamos nesta seção envolve uma série de considerações. No entanto, o algoritmo decorrente é bastante simples (veja fig. 3.4).

$$
\begin{aligned}
& \text { P-VALOR(X, N, runs }) \\
& 1 \quad t \leftarrow R(\mathbf{X}, \mathbf{N}) \\
& 2 y \leftarrow \sum X_{i} \\
& 3 \mathbf{p} \leftarrow \mathbf{N} / \sum N_{i} \\
& 4 \quad c \leftarrow 0 \\
& 5 \text { for } i \leftarrow 1 \text { to runs } \\
& 6 \text { do } \mathbf{W} \leftarrow \text { Vetor aleatório gerado por uma } \operatorname{Multi}(y, \mathbf{p}) \\
& 7 \text { if } R(\mathbf{W}, \mathbf{N}) \leq t \\
& 8 \quad \text { then } c \leftarrow c+1 \\
& 9 \text { return } c / \text { runs }
\end{aligned}
$$

Figura 3.4: Algoritmo para o cálculo do p-valor pelo método de Monte Carlo. Parâmetros de entrada: X: Vetor com as contagens de uma tag, $\mathbf{N}$ vetor com o número total de tags nas bibliotecas e runs número de amostragens para o cálculo do $p$-valor.

\subsection{Cálculo automático do nível crítico}

Um teste de significância consiste em aceitar ou rejeitar $H_{0}$ se o nível de siginificância for menor ou maior que um nível crítico $\alpha^{*}$. Segundo Kempthorne[55], o cientista deveria aceitar ou rejeitar a hipótese de acordo com um nível crítico de significância que ele 
acredite ser o melhor. Porém, para o teste de diferenciação em um conjunto de bibliotecas, são feitos milhares de testes. Portanto, seria difícil tomar uma decisão caso a caso. Esse problema nos levou a criar um procedimento automático para o cálculo do nível crítico.

O nível crítico define uma região $R$ no espaço amostral, para a qual a hipótese nula é rejeitada, e uma região de aceitação A, em que a hipótese nula é aceita. A escolha do nível crítico pode gerar dois tipos de erro:

1. Erro do tipo I: Rejeitar a hipótese nula quando ela é verdadeira. Este erro também é chamado de falso positivo.

2. Erro do tipo II: Aceitar a hipótese nula quando ela é falsa. Também chamado de falso negativo.

As probabilidades desses erros são usualmente indicadas respectivamente como:

$$
\begin{aligned}
& \alpha=\mathbb{P}\left[\mathbf{x} \in R \mid H_{0} \text { é verdadeiro }\right] \\
& \beta=\mathbb{P}\left[\mathbf{x} \in A \mid H_{0} \text { é falso }\right]
\end{aligned}
$$

Segundo DeGroot[38], um teste de significância ótimo é aquele que minimiza uma combinação linear $\gamma=a \alpha+b \beta$. Os valores $a$ e $b$ servem para ponderar entre os tipos de erros, pois, muitas vezes, errar de uma maneira ou de outra acarreta perdas diferentes.

O p-valor pv $=\mathbb{P}\left(\mathrm{T} \leq t \mid H_{0}\right)$ é exatamente o erro do tipo I: $\alpha(\delta)=\mathbb{P}\left(S \leq \alpha \mid H_{0}\right)$. Portanto, escolher um valor de corte $\alpha=0,05$ significa limitar o erro do tipo I, mas o erro do tipo II pode variar livremente. Além disso, quando o número de observações é muito grande, $o p$-valor tende a ficar muito pequeno[16]. Desse modo, utilizar um valor de corte fixo é injusto com a hipótese alternativa nos casos em que existem muitas observações.

Para encontrar o melhor valor de corte $\alpha$, foi calculado $\hat{\alpha}_{k}(y)$, uma função do número de observações $y$ e do total de bibliotecas $k$, que minimiza $a \hat{\alpha}(y)+b \hat{\beta}(y)$. 


\subsubsection{Cálculo de $\alpha$ e $\beta$}

Para um determinado nível crítico $C$, tem-se a região de aceitação $A_{C}$ e a região crítica $R_{C}$. O erro do tipo I $\alpha_{c}$ implicado por este corte é simplesmente a probabilidade da região crítica $\alpha_{c}=1-\mathbb{P}\left(A_{c}\right)$. Utilizando a hipótese nula $\left[\frac{1}{k}, \cdots, \frac{1}{k}\right]$ tem-se o máximo da variância e, conseqüentemente, o limite superior para $\alpha_{c}$.

Para o cálculo de $\beta_{c}$ utiliza-se a definição:

$$
\beta_{c}=\mathbb{P}\left[\mathbf{w} \in A_{c} \mid H_{1}\right]=\frac{\mathbb{P}\left[\mathbf{w} \in A_{C}, H_{1}\right]}{\mathbb{P}\left[H_{1}\right]}
$$

Que éigual à soma, para todos os pontos de $A_{C}$, da probabilidade da hipótese alternativa ser verdadeira:

$$
\frac{\sum_{\mathbf{w} \in A_{C}} \mathbb{P}\left[\mathbf{w} \in H_{1}\right]}{\int_{H_{1}} f(\mathbf{p}) d \mathbf{p}}
$$

Como $H_{0}$ é somente um ponto, podemos tomar $H_{1}=\Theta$ e calcular o valor médio de $\beta_{c}$ para cada $\mathbf{w} \in A_{c}$ :

$$
\frac{\sum_{\mathbf{w} \in A_{C}} \int_{\Theta} \mathbb{P}[\mathbf{w} \mid \mathbf{p}] f(p) d \mathbf{p}}{\int_{H_{1}} f(p) d \mathbf{p}}
$$

Considerando uma $\operatorname{Beta}(1, \cdots, 1)$ como priori para $\mathbf{p}$, a integral do numerador da equação 3.16 é

$$
\left(\begin{array}{c}
n \\
x_{1}, \cdots, x_{k}
\end{array}\right) \int_{\Theta} p_{1}^{x_{1}} \cdots p_{k}^{x_{k}} \frac{1}{B(1, \cdots, 1)} d \mathbf{p}
$$

Calculando esta integral tem-se:

$$
\frac{1}{B(1, \cdots, 1)} \frac{\Gamma(y+1)}{\prod_{j=1}^{k} \Gamma\left(w_{j}+1\right)} \frac{\prod_{j=1}^{k} \Gamma\left(w_{j}+1\right)}{\Gamma(y+k)}=\frac{\Gamma(y+1)}{\Gamma(y+k)}
$$


Como 3.18 não depende de $\mathbf{w}$, a somatória da equação 3.16 é simplesmente $\beta_{c}=\frac{N_{c}}{N_{k}(y)}$, onde $\mathrm{N}_{c}$ é a cardinalidade de $A_{c}$ e $N_{k}(y)$ é o número total de pontos do espaço amostral: $\mathrm{N}_{k}(y)=\left(\begin{array}{c}y+k-1 \\ k-1\end{array}\right)$.

Para todos os valores de corte foi calculdo o valor de $\alpha_{c}$ e $\beta_{c}$ e escolhido o valor que minimiza a combinação linear $a \alpha_{c}+b \beta_{c}$. Esse cálculo foi repetido para diversas freqüências totais $y$, número de bibliotecas $k$ e duas combinações lineares dos erros: $a=1$ e $b=1$; e $a=4$ $\mathrm{e} b=1$. A escolha de $a=4$ na segunda combinação tem por objetivo calcular níveis críticos mais estringentes em relação à escolha das tags diferencialmente expressas, pois as tags escolhidas tornam-se candidatas a futuras análises, e se a tag é um falso positivo há um desperdício de tempo e dinheiro em analisá-la. Desta forma, é preferível errar mais com falsos negativos do que com falsos positivos.

Devido ao crescimento exponencial $\mathrm{N}_{k}(y)$, só foi possível calcular $\hat{\alpha}_{k}(y)$ para um número limitado de valores de $k$ e $y$.

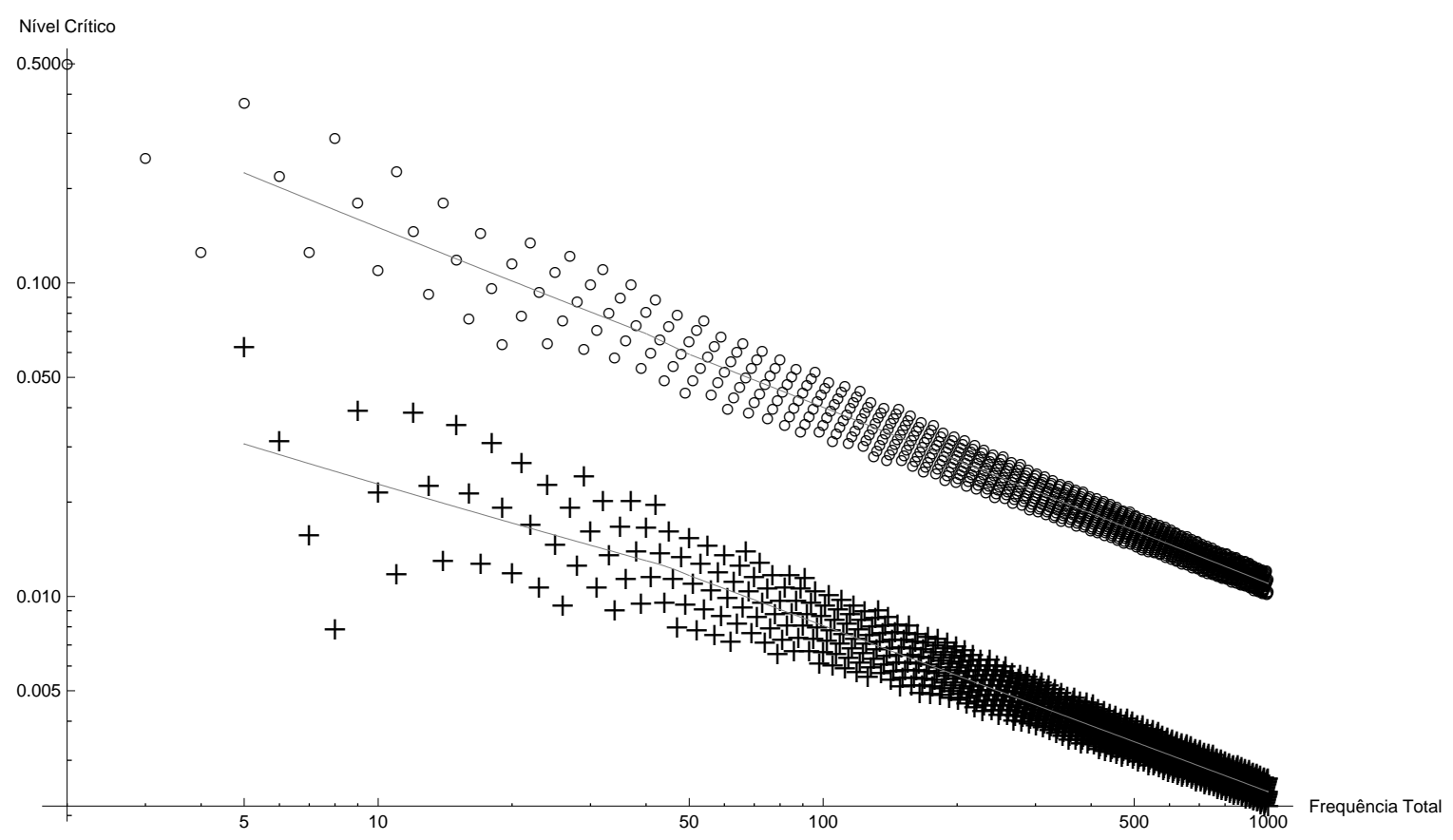

Figura 3.5: Gráfico dilog com os valores de corte simulados e a função do nível crítico para comparação de duas bibiliotecas. A função de corte esta indicada por uma linha cinza, os valores críticos para a combinação $\alpha+\beta$ por circulos, e os valores críticos para a combinação $4 \alpha+\beta$ por cruzes. 


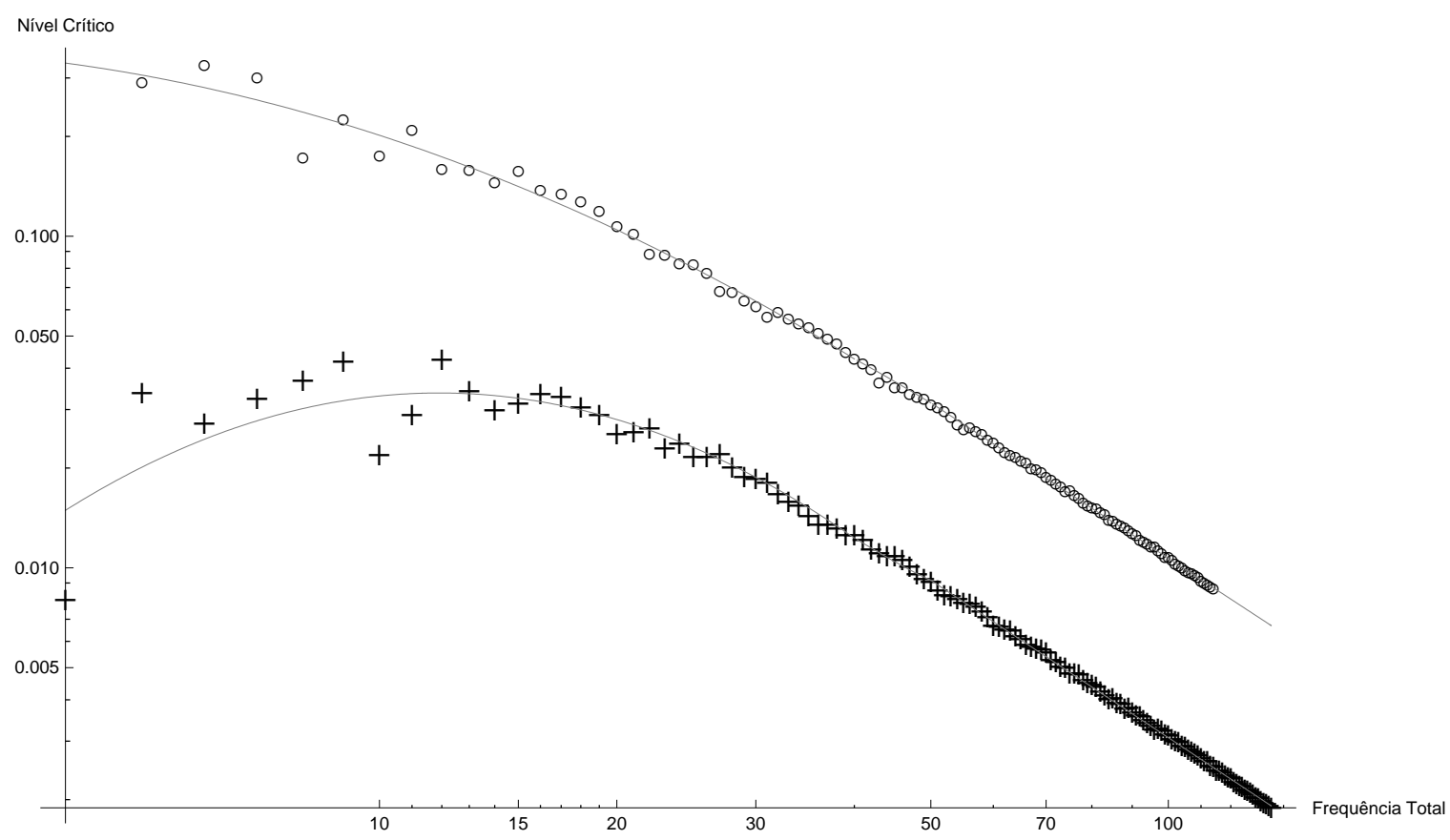

Figura 3.6: Gráfico dilog com os valores de corte simulados e a função do nível crítico para comparação de cinco bibiliotecas. A função de corte esta indicada por uma linha cinza, os valores críticos para a combinação $\alpha+\beta$ por circulos, e os valores críticos para a combinação $4 \alpha+\beta$ por cruzes.

Para extrapolar o resultado de $\hat{\alpha}_{k}(y)$ para outros valores, fez-se um ajuste de mínimos quadrados por partes. A primeira parte dos gráficos, com $y \leq 50$, foi ajustada por uma parábola

$$
\log \alpha_{K}^{(1)}(y)=a_{k} \log (y)^{(2)}+b_{k} \log (y)+c_{k}
$$

e a segunda parte foi ajustada por uma reta

$$
\log \alpha_{K}^{(2)}(y)=u_{k}+v_{k} \log (y)
$$

Desta forma, obtem-se a melhor precisão no corte dos pontos de baixa contagem, sem perder a possibilidade de extrapolar o corte para valores grandes de $y$. Os parâmetros dos ajustes para $a=4$ e $b=1$ estão na tabela 3.1, e para $a=1$ e $b=1$ na tabela 3.2. Foi construída, a seguir, uma função contínua por partes (eq. 3.19), que combina os ajustes nas duas regiões. O resultado deste ajuste para as duas combinações de $\alpha$ e $\beta$ consideradas, e 
para a comparação de duas e cinco bibliotecas estão representados nas figuras 3.5 e 3.6.

$$
\alpha_{k}^{*}(y)= \begin{cases}\alpha_{k}^{(1)}(y) & \text { para } y<40 \\ (1-\lambda) \alpha_{k}^{(1)}(y)+\lambda \alpha_{K}^{(2)}(y) & \text { para } 40 \leq y<50 \\ \alpha_{k}^{(2)}(y) & \text { para } y \geq 50\end{cases}
$$

\begin{tabular}{rrrrrr}
\hline $\mathrm{k}$ & $a_{k}$ & $b_{k}$ & $c_{k}$ & $u_{k}$ & $v_{k}$ \\
\hline 2 & 0.00957978 & -0.463118 & -2.76474 & -2.37781 & -0.530119 \\
3 & -0.304365 & 1.18976 & -4.60784 & -0.713611 & -0.968513 \\
4 & -0.931159 & 5.00318 & -10.1863 & 0.385118 & -1.28105 \\
5 & -0.685327 & 3.39467 & -7.59502 & 1.47602 & -1.57657 \\
6 & -0.914225 & 4.84175 & -9.81444 & 1.93518 & -1.70783 \\
\hline
\end{tabular}

Tabela 3.1: Valores dos parâmetros ajustados das funções de nível crítico que minimizam $4 \alpha+\beta$ para diferentes números de bibliotecas $k \cdot \log \alpha_{K}^{(1)}(y)=a_{k} \log (y)^{(2)}+b_{k} \log (y)+c_{k}$ e $\log \alpha_{K}^{(2)}(y)=u_{k}+v_{k} \log (y)$

\begin{tabular}{rrrrrr}
\hline $\mathrm{k}$ & $a_{k}$ & $b_{k}$ & $c_{k}$ & $u_{k}$ & $v_{k}$ \\
\hline 2 & 0.00748022 & -0.607463 & -0.53588 & -0.629139 & -0.561742 \\
3 & -0.226299 & 0.503742 & -1.7504 & 0.677628 & -0.968169 \\
4 & -0.215143 & 0.334093 & -1.38061 & 1.79399 & -1.30545 \\
5 & -0.248689 & 0.369967 & -1.13529 & 2.62984 & -1.55664 \\
\hline
\end{tabular}

Tabela 3.2: Valores dos parâmetros ajustados das funções de nível crítico que minimizam $\alpha+\beta$ para diferentes números de bibliotecas $k . \log \alpha_{K}^{(1)}(y)=a_{k} \log (y)^{(2)}+b_{k} \log (y)+c_{k}$ e $\log \alpha_{K}^{(2)}(y)=u_{k}+v_{k} \log (y)$

\subsection{Implementação}

O método descrito foi implementado em um software em C chamado kemp, em homenagem ao Prof. Oscar Kempthorne. Utilizou-se a biblioteca GSL[48] para a geração de vetores aleatórios com distribuição multinomial, empregando-se o algoritmo proposto por C. S. Davis[35]. Para a geração da densidade uniforme foi utilizado o MersenneTwister[66]. O número de sorteios na simulação foi fixado em 1 milhão. Em testes realizados, a incerteza no $p$-valor foi inferior a $10^{-4}$, e o tempo de execução foi inferior a 1 segundo por tag em um PC moderno (Athlon 64 X2 6000+).

Para melhorar o desempenho, o programa utiliza uma hash table ${ }^{1}$ [29] para armazenar

\footnotetext{
${ }^{1}$ Também conhecidos como dicionários, as Hash tables são estruturas de dados razoavelmente simples e que permitem buscas e inserções rápidas
} 
os p-valores já calculados e não recalcular tags que tenham o mesmo vetor de contagens. Ele também utiliza a biblioteca pthreds[71] para aproveitar computadores com múltiplas CPU's. Para evitar conflito no acesso à hash table com os valores calculados, toma-se o cuidado de proteger o acesso a esta com um mutex ${ }^{2}$. O programa está disponível sob licença GPL no site:

http://code.google.com/p/kempbasu/

\subsubsection{Consistência do teste em relação à remoção de tags de baixa contagem}

No conjunto de dados referente à doença de Alzheimer, foram detectados 969 tags diferencialmente expressas. Ao se remover as tags de baixa contagem (utilizando a normalização explicada na seção 2.1, e valor de corte 4 ), o valor de $N_{j}$ diminui em média $33 \%$, mas ao se analisar esse conjunto reduzido de tags, o total de tags diferencialmente expressas foi de 967 tags, sendo que somente 58 tags não eram comuns entre os dois grupos. Todas as tags não compartilhadas entre o conjunto de dados completo e o conjunto reduzido tinham score menor que 6, ou seja, mudanças no valor de $N_{j}$ não modificaram os resultados de score alto. Resultados similares são obtidos em análises de outros conjuntos de dados.

\subsection{Outros testes de significância}

O teste proposto compara diferenças de expressãos entre $k$ bibliotecas distintas. Alguns métodos em uso são limitados à comparação de somente duas bibliotecas, como o método de Lal[58] ou o teste exato de Fisher[98]. Outros métodos fazem a comparação entre grupos de bibliotecas em duas condições diferentes, por exemplo, bibliotecas geradas de tecidos normais contra bibliotecas geradas de tecidos tumorais[13, 90, 12, 63, 73, 102, 82].

Greller e Tobin propõem um método para detectar se o nível de expressão em uma biblioteca é diferente do nível nas demais[49]. Esse método, na verdade, não é um teste

\footnotetext{
${ }^{2}$ Dispositivo de exclusão mútua
} 
de diferença de expressão, mas um detector de outliers ${ }^{3}$.

Detalharemos a seguir alguns métodos similares ao método proposto e que estão descritos na literatura.

\subsubsection{Audic e Claverie}

Audic e Claverie[10] propõem um teste de significância para duas bibliotecas. O nível de significância proposto é a probabilidade de observar $X_{2}=x_{2}$, dado que $X_{1}=x_{1}$ :

$$
\mathbb{P}\left(X_{2}=x_{2} \mid X_{1}=x_{1}\right)=\left(\frac{N_{2}}{N_{1}}\right)^{x_{2}} \frac{\left(x_{1}+x_{2}\right) !}{x_{1} ! x_{2} !\left(1+\frac{N_{2}}{N_{1}}\right)^{\left(x_{1}+x_{2}+1\right)}}
$$

Os autores definem um teste de hipótese baseado no intervalo de confiança. Para uma determinada probabilidade $\epsilon$ define-se o intervalo $[a, b]$, de modo que a região fora do intervalo tenha probabilidade $2 \epsilon$ (eq 3.21).

$$
\begin{aligned}
& \epsilon=\mathbb{P}\left(x_{2} \leq a \mid x_{1}\right)=\sum_{x_{2}=0}^{a} \mathbb{P}\left(x_{2} \mid x_{1}\right) \\
& \epsilon=\mathbb{P}\left(x_{2} \geq b \mid x_{1}\right)=\sum_{x_{2}=b}^{\infty} \mathbb{P}\left(x_{2} \mid x_{1}\right)
\end{aligned}
$$

\subsubsection{Método Bayesiano de Chen}

Chen at al[24] propõem outro método para a comparação de duas bibliotecas de mesmo número total de tags.

Tomando-se o nível de expressão das duas bibliotecas $p_{1}$ e $p_{2}$, calcula-se o parâmetro $z=\frac{p_{1}}{p_{1}+p_{2}}$ limitado ao intervalo [0,1]. Com o modelo binomial para as contagens $x_{1}$ e $x_{2}$, tendo como priori uma $z \sim \operatorname{Beta}(\alpha, \beta)$, chega-se, como explicado na seção 2.2.2, a uma posteriori $z \mid x_{1}, x_{2} \sim \operatorname{Beta}\left(\alpha+x_{1}, \beta+x_{2}\right)$. Por fim, calcula-se a probabilidade de $p_{1}$ ser pelo menos $\mathrm{F}$ vezes maior que $p_{2}$ integrando a posteriori de $L=\frac{F}{F+1}$ até 1 :

\footnotetext{
${ }^{3}$ outlier é uma observação que está muito fora do padrão do resto dos dados.
} 


$$
P(z \geq L)=\frac{\Gamma\left(\alpha+x_{1}+\beta+x_{2}\right)}{\Gamma\left(\alpha+x_{1}\right) \Gamma\left(\beta+x_{2}\right)} \int_{L}^{1} z^{\alpha+x_{1}-1}(1-z)^{\beta+x_{2}-1}
$$

Chen observa que z é usualmente concentrado em torno do 0,5. Portanto, ele escolhe os parâmetros $\alpha=\beta=2$.

Lal et al[58] propõem uma alteração ao método de Chen para bibliotecas com tamanhos $N_{1}$ e $N_{2}$ diferentes (eq. 3.24). Também é proposto o valor $\alpha=\beta=3$ para os hiperparâmetros. Este é o método utilizado no site SAGEmap ${ }^{4}$ para a comparação de expressão.

$$
\xi\left(z \mid x_{1}, x_{2}, N_{1}, N_{2}\right) \propto \frac{z^{x_{1}+\alpha}(1-z)^{x_{2}+\beta}}{\left[1+\left(\frac{N_{1}}{N_{2}}-1\right) z\right]^{x_{1}+x_{2}}}
$$

\subsubsection{Estatística $\mathrm{R}$ de Stekel}

Stekel et al[84] propõem o uso do teste da razão de verossimilhança. Supondo o modelo de Poisson eles calculam a verossimilhança sobre a hipótese de não diferenciação:

$$
L_{i}^{0}=\prod_{j=1}^{k} \frac{e^{f_{i} N_{j}}\left(f_{i} N_{j}\right)^{x_{i j}}}{x_{i j} !}
$$

com $f$ sendo a proporção esperada para a tag $i$, calcula-se a estimativa de máxima verossimilhança de $f_{i}$ :

$$
f_{i}=\frac{\sum_{j=1}^{k} x_{i j}}{\sum_{j=1}^{k} N_{j}}
$$

A verossimilhança máxima sob a hipótese alternativa ocorre quando a freqüência em cada biblioteca é $x_{i j} / N_{j}$, portanto:

$$
L_{i}^{1}=\prod_{j=1}^{k} \frac{e^{-x_{i j}} x_{i j}^{x_{i j}}}{x_{i j} !}
$$

\footnotetext{
${ }^{4}$ http://www.ncbi.nlm.nih.gov/SAGE
} 
Os autores chamam de estatística $R_{i}$ o log da razão de verossimilhança sob as hipóteses:

$$
R_{i}=\log \left(\frac{L_{i}^{1}}{L_{i}^{0}}\right)=\sum_{j=1}^{k} x_{i j} \log \left(\frac{x_{i j}}{N_{j} f_{i}}\right)
$$

\subsubsection{Teste do $\chi^{2}$ de homogeneidade}

Além dos testes criados especificamente para a contagem de tags, alguns testes clássicos para tabelas de contingência são comumente empregados. O teste $\chi^{2}$ de homogeneidade é um destes. Testa-se a mesma hipótese nula do teste proposto neste capítulo: $H_{0}: p_{i 1}=$ $\cdots=p_{i k}$. O teste é implementado, contruindo-se para a linha da matriz $\mathbb{X}$ uma tabela de contingência $\mathbb{W}$ (eq. 3.3), com as somas marginais $y_{i}$ e $N_{j}$ e a soma total $N$.

$$
\begin{array}{lcccc|c}
\text { Gene i } & x_{i 1} & x_{i 2} & \cdots & x_{i k} & y_{1} \\
\text { Outros genes } & N_{1}-x_{i 1} & N_{2}-x_{i 2} & \cdots & N_{k}-x_{i k} & y_{2} \\
\hline & N_{1} & N_{2} & \cdots & N_{k} & N
\end{array}
$$

Tabela 3.3: Tabela de contingência $\mathbb{W}$ para teste de diferenciação.

Calcula-se o valor da estatística $Q$ :

$$
Q=\sum_{i=1}^{2} \sum_{j=1}^{k} \frac{\left(w_{i j}-E_{i j}\right)^{2}}{E_{i j}}
$$

onde $E_{i j}$ é o valor esperado de $w_{i j}$ sobre $H_{0}$, como $w_{i j}$ é uma multinomial $E_{i j}=y_{1} p_{i j}$, e como o valor de $p_{i j}$ é desconhecido, utiliza-se a estimativa de máxima verossimilhança $\hat{p}_{i j}=\frac{N_{j}}{N}$. Portanto:

$$
Q=\sum_{i=1}^{2} \sum_{j=1}^{k} \frac{\left(w_{i j}-\hat{E}_{i j}\right)^{2}}{\hat{E}_{i j}}
$$

Onde:

$$
\hat{E}_{i j}=\frac{N_{j} y_{i}}{N}
$$


A estatística $Q$ tem assintoticamente distribuição $\chi^{2}$ com $k-1$ graus de liberdade, portanto o p-valor é a área da calda da distribuição $\chi^{2}$ dos valores mais extremos do que Q.

\subsubsection{O teste proposto Kemp em relação à outros testes}

Dos testes apresentados, somente o teste $\chi^{2}$ e da razão de verossimilhança permitem a comparação de qualquer número de bibliotecas. O teste proposto nesta tese é superior ao teste da razão de verossimilhança, pois o p-valor é uma grandeza mais interpretável do que o valor da razão de verossimilhança. Devido a sua natureza assintótica, o teste do $\chi^{2}$ não é apropriado quando o número de observações é pequeno[26, 97, 57, 47, 80]. Para um conjunto de 4 bibliotecas de SAGE (código GSE6677 no GEO) foi calculado o p-valor pelo nosso método e pelo método do $\chi^{2}$ para aproximadamente 60 mil tags. Na figura 3.7 vê-se um gráfico com ambos os p-valores para as tags com alta expressão $(y>50)$.Vê-se que o valor calculado pelo $\chi^{2}$ é próximo ao do método proposto. Para as tags de menor expressão $(y \leq 50)$, existe uma divergência muito maior entre os métodos.

Existe a possibilidade de combinar o $\chi^{2}$ com outro teste, utilizando o $\chi^{2}$ para tags com alta expressão e o método alternativo para as tags de baixa expressão. Porém, essa abordagem implica julgar as tags por meio de duas medidas diferentes. O método proposto evita esse problema, pois não utiliza nenhum resultado assintótico, o que o torna aplicável tanto para tags com baixa expressão quanto para tags com alta expressão.

\subsection{Aplicações}

\subsubsection{Tecidos de tumores de cabeça e pescoço}

O carcinoma de tecidos escamosos de cabeça e pescoço (HNSCC, sigla em inglês) é um dos tumores mais comuns em humanos. Ele está associado ao consumo de álcool e de tabaco, e representa uma grande problema de saúde no mundo, com aproximadamente 


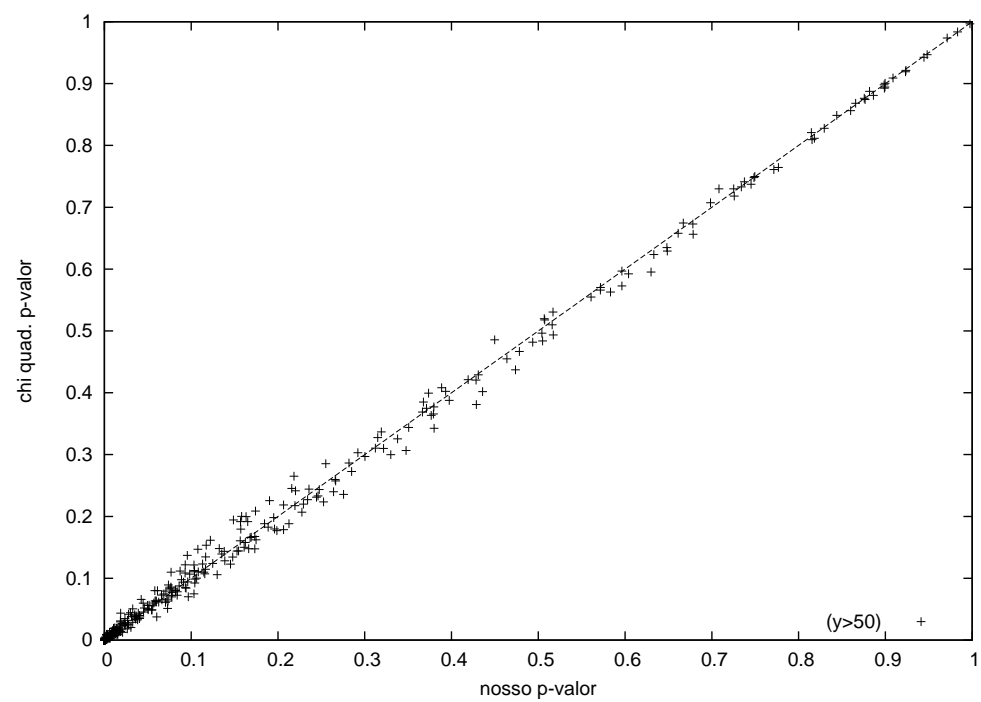

Figura 3.7: Gráfico do $\mathrm{p}$-valor proposto versus o p-valor calculado pelo método do $\chi^{2}$ para tags com freqüência total maior que $50(y>50)$.

650 mil casos e 90 mortes por ano. Quando detectado precocemente, o HNSCC tem uma taxa de $75 \%$ de cinco anos de sobrevida. Porém, a maioria dos pacientes já apresentam metástase na época do diagnóstico, o que reduz a taxa de sobrevivência para 35\%[25].

Atualmente, existem poucos marcadores moleculares que podem ser usados com acurácia e confiança como indicadores de carcinomas de cabeça e pescoço com potencial metastático. Com o objetivo de identificar genes diferencialmente expressos envolvidos no desenvolvimento e na progressão de carcinomas de células escamosas de laringe (LSCC, single me inglês), The Brazilian Head and Neck Genome Project ${ }^{5}$ produziu um conjunto de 3 bibliotecas de SAGE, sendo que uma de um carcinoma metastático, outra de um carcinoma não metastáticos e uma amostra normal da mucosa (trabalho submetido à BMC Medical Genome). Aproximadamente $54 \mathrm{mil}$ tags foram seqüênciadas. A comparação feita pelo método kemp detectou 1.216 tags diferencialmente expressas entre as bibliotecas normais e tumorais, e 894 tags diferencialmente expressas entre carcinomas metastáticos

\footnotetext{
${ }^{5}$ http://ctc. fmrp.usp.br/ClinicalGenomics/cp/
} 


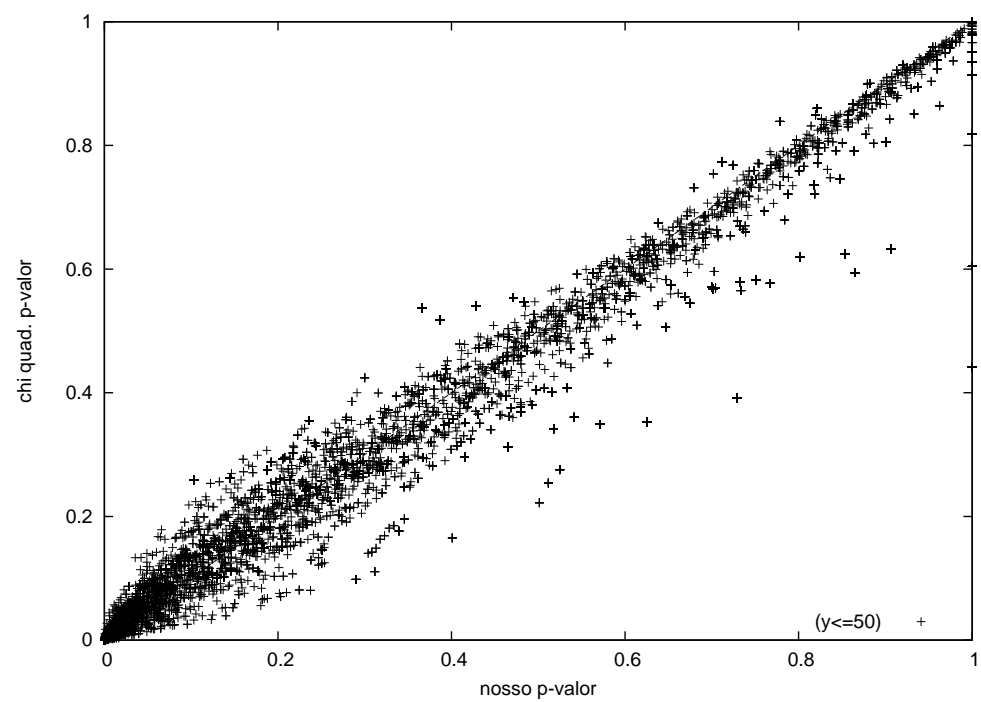

Figura 3.8: Gráfico do p-valor proposto versus o p-valor calculado pelo método do $\chi^{2}$ para tags com freqüência total menor ou igual a $50(y \leq 50)$.

e não metastáticos. A diferença de expressão de três genes detectados pelo nosso método (KRT31,BST2,MFAP2) foram confirmadas por RT-PCR, assim como a não diferença do gene GNA15. Em especial, é sabido que os genes BST2 e MFAP2 estão envolvidos em processos tumorais $[93,70]$. 


\section{Capítulo 4}

\section{Basu: Teste Estatístico Bayesiano para a Comparação da expressão de Tags}

O primeiro teste proposto calcula a significância por meio da ordenação dos pontos do espaço amostral pela razão de verossimilhança. Neste capítulo, será apresentado um segundo teste de significância Bayesiano em que somente o espaço paramétrico é considerado no cálculo do nível de significância.

\subsection{FBST}

Um problema do teste clássico proposto no capítulo 3 reside no fato de que as hipóteses do teste são construídas no espaço paramétrico, porém a significância é calculada no espaço amostral, mais específicamente, nos pontos não observados do espaço amostral. Pereira e Stern[36] propõe um teste Bayesiano que considera somente a distribuição a posteriori do parâmetro no cálculo da significância, ou seja, um teste que calcula a significância no espaço paramétrico, e não no espaço amostral.

Para um parâmetro $\theta \in \Theta$, define-se, para um valor $\phi$, o conjunto: 


$$
T_{\phi}=\mathbb{P}[\theta \in \Theta \mid \xi(\theta)>\phi]
$$

A credibilidade de $T_{\phi}$ é a probabilidade a posteriori:

$$
\kappa=\int_{T_{\phi}} f(\theta \mid x) d \theta
$$

Seja $\phi^{*}=\xi\left(\theta^{*}\right)$, onde $\theta^{*}=\operatorname{argmax}_{\theta \in H_{0}} \xi(\theta)$, é o valor máximo da densidade a posteriori da hipótese nula. A significância de $H_{0}$ é o complemento de $\kappa^{*}=\mathbb{P}\left[T_{\phi^{*}}\right]$, ou seja:

$$
E v\left(H_{0}\right)=1-\kappa^{*}=1-\int_{T_{\phi^{*}}} \xi(\theta \mid x) d \theta
$$

Graficamente, o conjunto $T_{\phi^{*}}$ é o conjunto tangente ao máximo de $H_{0}$ (figura 4.1 ). O teste tem uma segunda interpretação: se a probabilidade do conjunto $T_{\phi^{*}}$ é "grande", isso significa que o conjunto nulo está em uma região de baixa probabilidade e a evidência contida nos dados é contrária à hipótese nula. Por outro lado, se a probabilidade de $T_{\phi^{*}}$ é "pequena", o conjunto nulo está em uma região de alta probabilidade e a evidência contida nos dados é favorável à hipótese nula.

\subsection{Distribuição normal-logística}

Para aplicar o FBST sobre $H_{0}: p_{i 1}=\cdots=p_{i k}$ seria possível calcular as marginais de $p_{i j}$, uma $\operatorname{Beta}\left(\alpha_{i j}+x_{i j}, \beta+N_{j}-x_{i j}-\alpha_{i j}\right)$. O problema é que, para o valor de $N_{j}$ usual, a densidade beta se torna muito concentrada em torno da média, criando uma dificuldade numérica para o cálculo da evidência.

Aitchison[4], Lindley[60], sugeriram que a densidade $\operatorname{Dir}\left(\xi_{1}, \cdots, \xi_{d+1}\right)$ pode ser numericamente aproximada por uma normal-logística $L_{d}(\mu, \Sigma)$ (eq. 4.5), com os seguintes parâmetros: 


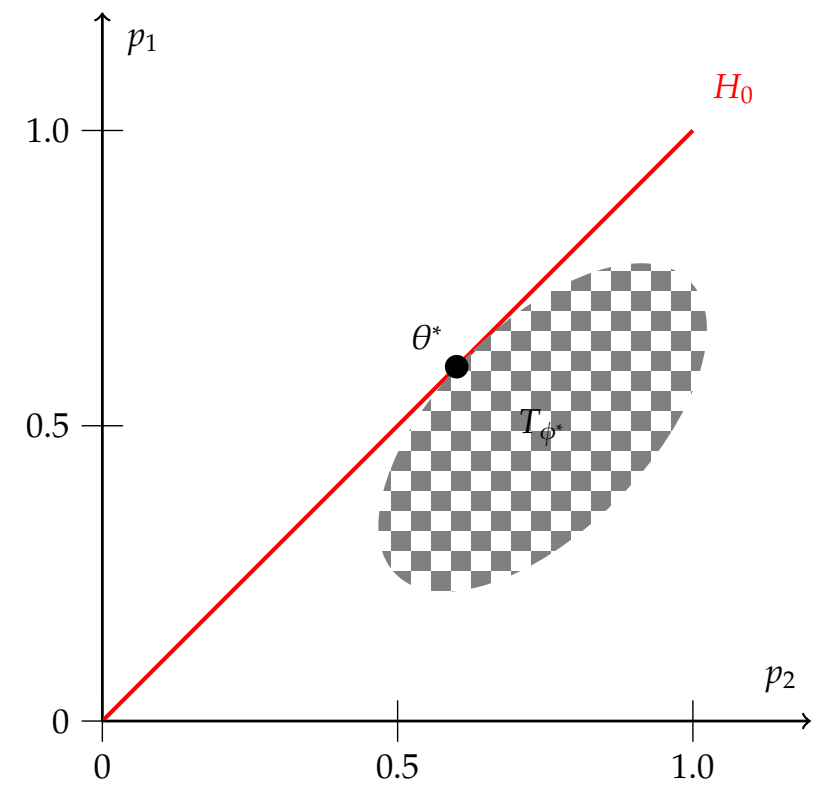

Figura 4.1: Ilustração do FBST. A reta indica $H_{0}$, o ponto $\theta^{*}$ indica o máximo de $H_{0}$ e a região quadriculada indica o conjunto tangete $T_{\phi}^{*}$.

$$
\mu_{i}=\psi\left(\xi_{i}\right)-\psi\left(\xi_{d+1}\right) \quad \sigma_{i i}=\psi^{\prime}\left(\xi_{i}\right)+\psi^{\prime}\left(\xi_{d+1}\right) \quad \sigma_{i j}=\psi^{\prime}\left(\xi_{d+1}\right) \quad(i \neq j)
$$

Onde $\psi(x)=\Gamma^{\prime}(x) / \Gamma(x)$ é a função Digama e $\psi^{\prime}(x)=\frac{d \Gamma(x)}{d x^{2}}$ é a função Trigama. Uma discussão detalhada sobre a obtenção deste resultado pode ser encontrada na dissertação de mestrado de William Rodrigues[83].

$$
\begin{aligned}
& f(\mathbf{p} \mid \mu, \Sigma)= \\
& \quad|2 \pi \boldsymbol{\Sigma}|^{-\frac{1}{2}}\left(\prod_{i=1}^{d+1} p_{i j}\right)^{-1} \exp \left\{-\frac{1}{2}\left[\log \left(\frac{\mathbf{p}_{j}}{p_{d+1, j}}\right)-\mu_{j}\right]^{T} \boldsymbol{\Sigma}^{-1}\left[\log \left(\frac{\mathbf{p}_{j}}{p_{d+1, j}}\right)-\mu_{j}\right]\right\}
\end{aligned}
$$

Portanto se $p_{i j} \sim \operatorname{Beta}\left(x_{i j}, N_{J}-x_{i j}\right.$, a variável $\mathbf{y}_{i j}=\log \left(\frac{\mathbf{p}_{p j}}{1-p_{i j}}\right)$ tem aproximadamente uma distribuição normal, ou seja, $y_{i} \approx N\left[\psi\left(x_{i j}+\alpha_{i}\right)-\psi\left(x_{d+1, j}+\alpha_{d+1}\right), \psi^{\prime}\left(x_{d+i, j}+\alpha_{d+1}\right)\right]$.

A densidade para a tag $i$ é o produto de $\mathrm{k}$ normais com parâmetros conhecidos. Como a hipótese nula de igualdade em y é equivalente à igualdade em $p$, pode-se testar $H_{0}^{\prime}$ : 
$y_{i 1}=\cdots=y_{i k}$ com FBST.

\subsection{Comparação entre os níveis de significância freqüentista e bayesi- ano}

Para comparar o nível de significância freqüêntista ( $p$-valor) com o bayesiano (e-valor) foram selecionados dois conjuntos de bibliotecas. O primeiro, Para 2 conjunto de 4 bibliotecas referentes a um estudo da doença de Alzheimer - código GSE6677 na base de dados GEO. Foram calculados os p-valores e os e-valores das tags com soma normalizada acima de 4. Os 10,460 pares $(p, e)$, com respectivamente os valores do p-valor e do e-valor, estão representados na figura 4.2. Para diversos testes de hipótese, o $p$-valor e o -valor estão ligados por uma função de distribuição Beta [79], por isso foram buscados os parâmetros desta distribuição que melhor ajustassem os dados. Para realizar este ajuste o p-valor foi dividido em intervalos de comprimento 0.4. Para cada invervalo, foi calculada a média ponderada pelo poder de expressão do e-valor. Sobre os pares $(\bar{e}, \bar{p})$, respectivamente a média do e-valor e o centro do intervalo do $p$-valor, foi feito o ajuste de mínimos quadrados da função de distribuição $\operatorname{Beta}(a, b)$, resultando nos valores $a=0,66$ e $b=1,036$. A função ajustada e os pares $(\bar{e}, \bar{p})$ estão na figura 4.3. A função ajustada também esta na figura 4.2.

Em uma segunda comparação, envolvendo 3 bibliotecas de pele (códigos LSAGE Skin Normal B hs0271, LSAGE Skin Melanoma B hs0274 e LSAGE Skin Cancer B hs0283 no projeto $\mathrm{CGAP}^{1}$ ) e mais de 70 mil tags, obteve-se um resultado similar aos do conjunto de dados de Alzheimer, com a ligação entre os e-valor e o $p$-valor dada por uma função de distribuição Beta, embora com parâmetros $a=0,746$ e $b=1,317$. Os valores calculados estão na figura 4.4, e a média ponderada dos e-valores, junto com a função ajustada, estão na figura 4.5 .

\footnotetext{
${ }^{1}$ http://cgap.nci.nih.gov/SAGE
} 


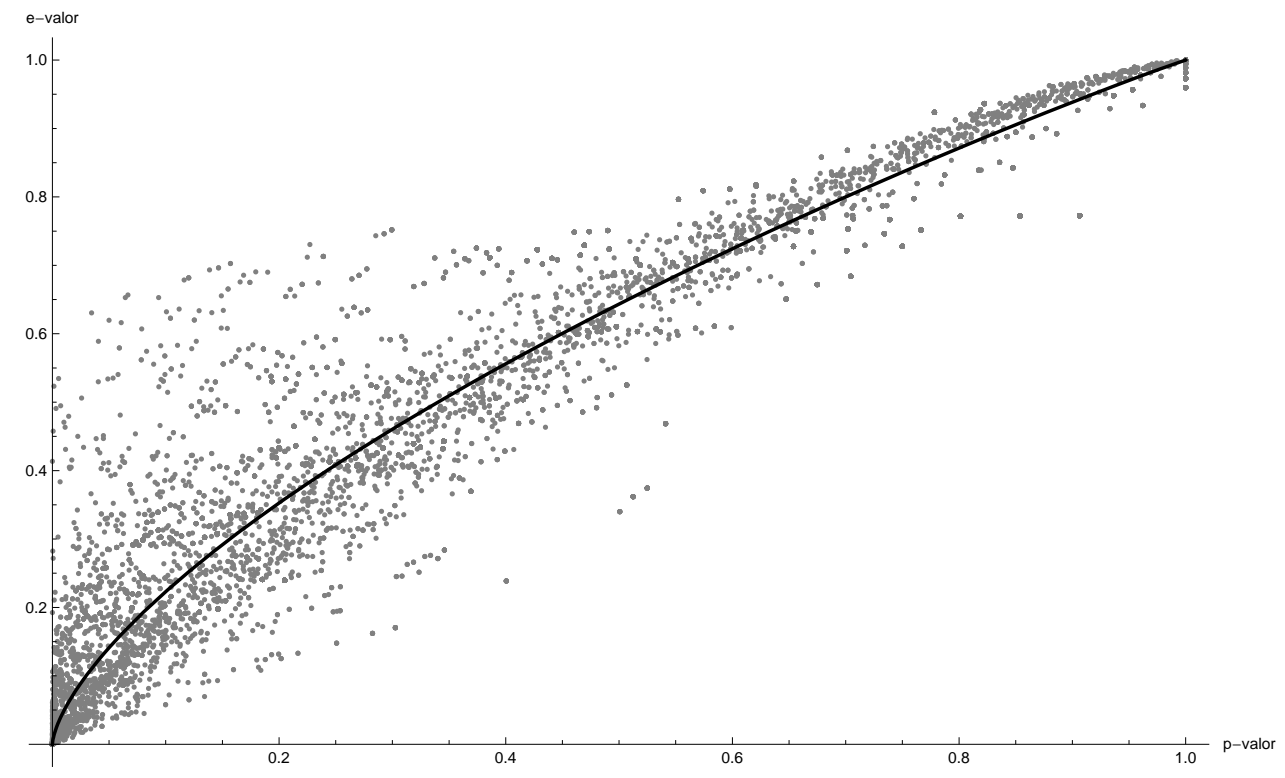

Figura 4.2: p-valor versus e-valor para o conjunto de dados de Alzheimer.

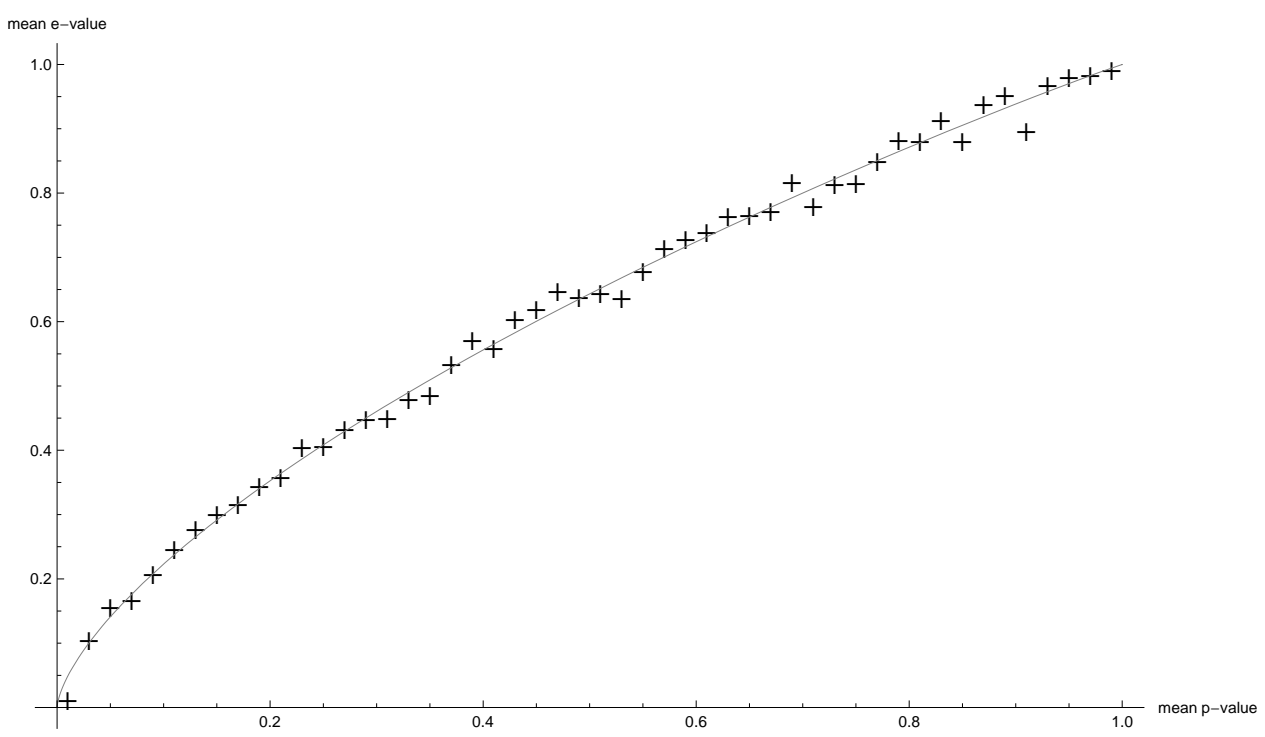

Figura 4.3: Ajuste da função de ligação entre $p$-valor e a média ponderada do e-valor para o conjunto de dados de Alzheimer. Os pares $(\bar{p}, \bar{e})$ estão indicados por cruzes, e a distribuição beta com parâmetros $a=0,66 \mathrm{e}$ $b=1,036$ esta indicada por uma linha cinza 


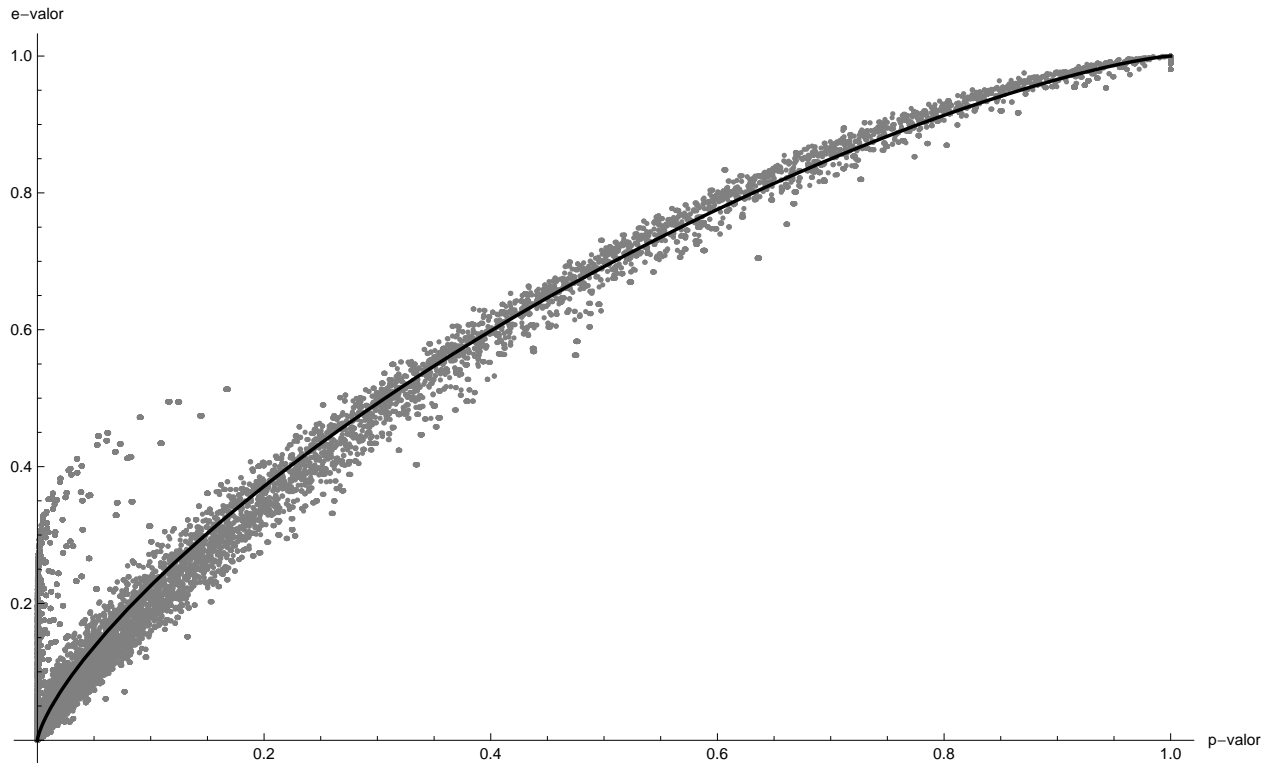

Figura 4.4: p-valor versus e-valor para o conjunto de dados de pele gerados por Solexa SAGE.

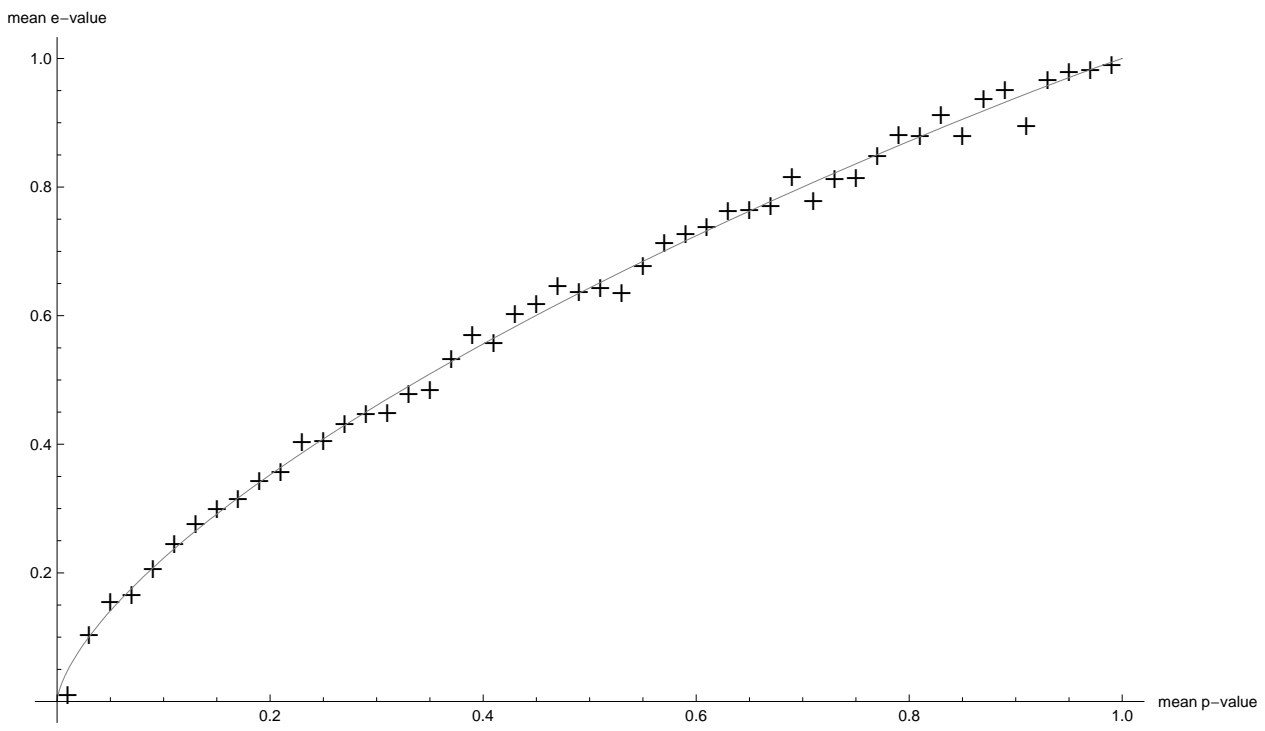

Figura 4.5: Ajuste da função de ligação entre $p$-valor e a média ponderada do $e$-valor para o conjunto de dados de pele. Os pares $(\bar{p}, \bar{e})$ estão indicados por cruzes, e a distribuição beta com parâmetros $a=0,746 \mathrm{e}$ $b=1,317$ esta indicada por uma linha cinza 


\section{Capítulo 5}

\section{Agrupamentos de Bibliotecas}

Nos capítulos 3 e 4, discutiu-se a análise tag a tag de um conjunto de bibliotecas de contagem. Neste capítulo, será discutida a análise global das bibliotecas pela construção de agrupamentos.

A análise de agrupamentos, ou clusters, busca, a partir de um conjunto de características, dividir uma coleção de objetos em grupos naturais. Em uma descrição bem simples, os algoritmos de agrupamento buscam juntar os objetos "próximos" e separar os objetos "distantes". Na figura 5.1, são mostrados três exemplos de agrupamentos para o valor de expressão de duas tags hipotéticas. Os agrupamentos podem ter diversas formas e diferentes dispersões. Para o cérebro humano é natural agrupar esses objetos segundo a distância entre eles. Mas qual distância utilizar? Para o nosso cérebro é natural utilizar a distância euclidiana, porém, dada a natureza dos dados, esta distância pode não ser a mais apropriada.

O conteúdo deste capítulo é uma expansão do que foi discutido no trabalho "Simcluster: clustering enumeration gene expression data on the simplex space" publicado em 2007[88]. 


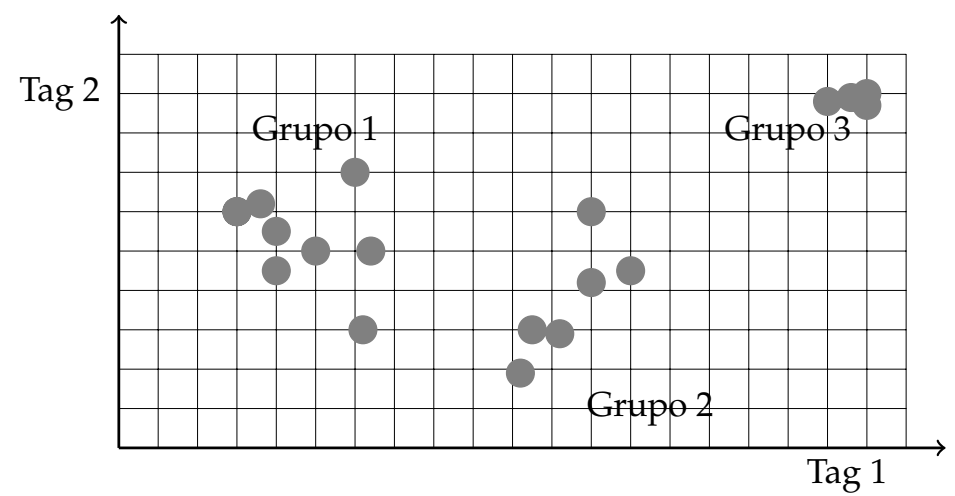

Figura 5.1: Exemplos de agrupamento hierárquico.

\subsection{Agrupamentos}

Definição 2. Agrupamentos são regiões contínuas do espaço que contêm uma alta densidade de pontos, separadas de outras regiões de alta densidade por regiões de relativa baixa densidade de pontos[45].

A definição acima é muito próxima da nossa percepção visual de agrupamentos em duas ou três dimensões. Em termos mais matemáticos, para uma amostra $\mathbb{X}=$ $\mathbf{x}_{1}, \mathbf{x}_{2}, \cdots, \mathbf{x}_{k}$, os agrupamentos são conjuntos disjuntos $C_{1}, \cdots, C_{m}$ de modo que os membros de cada agrupamento $C_{j}$ sejam mais similares (menos distantes) entre si do que em relação aos membros dos outros agrupamentos.

A definição anterior supõe uma medida de distância entre os vetores $x_{j}$. Para os vetores de contagem, a medida de distância é uma função $\Delta: \mathbb{N}_{+}^{n} \times N_{+}^{n} \rightarrow \mathbb{R}$. Para que $\Delta$ seja uma medida aceitável, algumas condições devem ser respeitadas:

1. $\Delta(a, b) \geq 0$;

2. $\Delta(a, b)=0$, se e somente se, $a=b$.

Caso a medida de distância respeite também as condições abaixo, ela é chamada de métrica.

1. $\Delta(a, b)=\Delta(b, a)$ (simetria) 
2. $\Delta(a, c) \leq \Delta(a, b)+\Delta(b, c)$ (desigualdade triangular)

Pode-se também exigir a propriedade bastante razoável e desejada de que a métrica seja invariante quanto a translações, ou seja, $\Delta(a+t, b+t)=\Delta(a, b)$, para qualquer par $a, b$ e translação $t$.

Algumas medidas de distância normalmente empregadas na análise de dados de expressão gênica são:

- Distância Euclidiana. Essa é a bem conhecida medida de distância do espaço euclidiano:

$$
\Delta_{e}(\mathbf{a}, \mathbf{b})=\sqrt{(\mathbf{a}-\mathbf{b})^{2}}
$$

- Correlação de Pearson. Essa medida é expressa como:

$$
\Delta_{p}(\mathbf{a}, \mathbf{b})=\frac{1-r(\mathbf{a}, \mathbf{b})}{2}
$$

Onde $r$ é a correlação de Pearson:

$$
r(\mathbf{a}, \mathbf{b})=\frac{(\mathbf{a}-\bar{a})(\mathbf{b}-\bar{b})}{\|(\mathbf{a}-\bar{a})\|\|(\mathbf{b}-\bar{b})\|}
$$

\subsubsection{Agrupamento por particionamento}

Uma classe de métodos de agrupamento são os agrupamentos por particionamento. Esses métodos buscam uma partição disjunta dos pontos fornecidos.

O k-médias[64] é um método de particionamento que agrupa n objetos em um número predefinido $\mathrm{k}$ de grupos, $k<n$. Esta partição é obtida pela minimização da variância intra-cluster total: 


$$
V=\sum_{i=1}^{k} \sum_{x_{j} \in C_{i}}\left(x_{j}-\mu_{i}\right)^{2}
$$

Onde $C_{i}, i=1,2, \cdots, k$ são os agrupamentos obtidos, e $\mu_{i}$ é o centróide, ou ponto médio, de todos os pontos $x_{j} \in C_{i}$. O $k$-médias gera um mosaico de células, centradas na média dos pontos de cada célula. Uma interpretação mais estatística é que ele é a maximização da esperança de uma mistura gaussiana.

Exceto para valores pequenos de $n$ e $k$, não é computacionalmente viável calcular o particionamento que minimiza globalmente a função 5.4. A solução heurística mais comum é um algoritmo de refinamento iterativo, conhecido como algoritmo de Lloyd[42]. O algoritmo inicia particionando os pontos em $\mathrm{k}$ grupos, aleatoriamente ou utilizando alguma heurística. Ele então calcula os pontos médios de cada grupo. Em seguida, são construídos novos grupos, associando cada ponto ao centróide mais próximo. Os centróides são recalculados para os novos agrupamentos. O algoritmo então se repete até que os pontos não troquem mais de grupo, ou alternativamente, os centróides não mudem mais.

Uma variação do $k$-médias é o método $k$-medóides[54], também conhecido como PAM (partition around medoids). O k-medóides utiliza como centro do agrupamento o medóide,

em vez do centróide. O centróide não é um ponto real do conjunto de entrada, ele é o valor médio dos outros pontos do grupo. Já o medóide é o ponto real mais próximo do centróide. Outra diferença é que o k-medóides minimiza a soma da distância intragrupo, em vez da variância intragrupo do $k$-médias.

\subsubsection{Agrupamento Hierárquico}

Outra técnica de agrupamento é o agrupamento hierárquico (hierarquical clustering), que organiza os dados em uma estrutura de grupos aninhados. Normalmente, o agrupamento hierárquico é representado por uma árvore chamada de dendrograma, como ilustrado na 
figura 5.2, onde é mostrado o agrupamento gerado a partir de um conjunto de bibliotecas de SAGE extraídas de tecidos de cólon (número de acesso GDS550 no GEO).

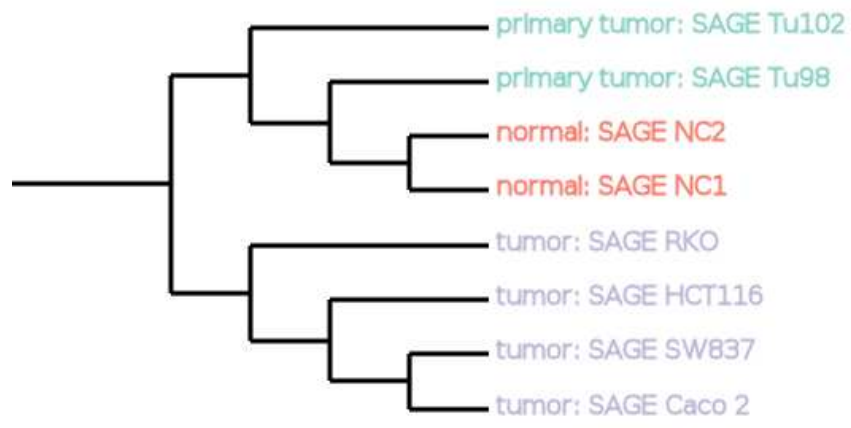

Figura 5.2: Exemplo de agrupamento em dados públicos de SAGE.

Os algoritmos de agrupamento hierárquico podem ser de natureza aglomerativa ou divisiva. Os algoritmos aglomerativos começam com cada ponto em seu próprio grupo, e sucessivamente esses grupos são juntados em grupos cada vez maiores, até restar um único grupo. Os algoritmos divisivos fazem o caminho inverso, partindo de um único grupo e dividindo os dados até cada amostra estar sozinha em um grupo.

O algoritmo de agrupamento recebe como entrada a matriz de distâncias $\mathrm{D}$, que é uma matriz $k \times k$ onde cada elemento contém o valor da distância $\Delta\left(\mathbf{x}_{i}, \mathbf{x}_{j}\right)$. A seguir, será descrito o algoritmo de agrupamento aglomerativo. A versão divisiva é similar, e não será descrita.

1. Inicialize $D_{0}=D(\mathbb{X})$ 
2. $t=0$

3. Encontre $C_{i}, C_{j}$ tal que $\Delta\left(C_{i}, C_{j}\right)=\min _{\forall r, s r \neq s} \Delta\left(C_{r}, C_{s}\right)$.

4. Una os grupos $C_{i}$ e $C_{j}$ em um novo grupo $C_{q}$.

5. $t=t+1$

6. Calcule a matriz de similaridade $D_{t}$ a partir de $D_{t-1}$

7. Volte para o passo 3 até que todos os vetores estejam no mesmo cluster.

O cálculo de $D_{t}$ consiste em remover as linhas $i$ e $j$ da matriz $D_{t-1}$ e adicionar uma nova coluna que representa a distância de $C_{q}$ em relação aos outros grupos. Os algoritmos que calculam a distância do novo grupo em relação aos demais são chamados algoritmos de ligação. Alguns deles são:

- Ligação singular (Single Linkage).

$$
\Delta\left(C_{q}, C_{s}\right)=\min \left[\Delta\left(C_{i}, C_{s}\right), \Delta\left(C_{j}, C_{s}\right)\right]
$$

- Ligação completa (Complete Linkage).

$$
\Delta\left(C_{q}, C_{s}\right)=\max \left[\Delta\left(C_{i}, C_{s}\right), \Delta\left(C_{j}, C_{s}\right)\right]
$$

\subsubsection{Análise de componentes principais (PCA)}

A análise de componentes principais (PCA: Principal Component Analysis) é uma transformação linear ortogonal que transforma os dados para um novo sistema de coordenadas, de modo que a projeção dos dados na primeira coordenada (chamada de primeira componente principal) tenha a maior variância, a projeção na segunda coordenada tenha a segunda maior variância, e assim por diante.

O PCA possui ligações com as técnicas de agrupamento. Segundo Ding e He[40] o PCA é a solução contínua para o escolha de grupos do k-médias. Outra aplicação do PCA é a 
redução de dimensionalidade através da projeção dos dados nas primeiras componentes principais[99].

Algebricamente as componentes principais são os autovetores da matriz de covariância dos dados. Os autovalores normalizados são a porção da variância representada pelo seu respectivo autovetor. Essa propriedade será utilizada para estimar o número de agrupamentos ótimo para os algoritmos de $k$-médias e $k$-medóides.

\subsection{O espaço Simplex}

Em diversas situações, as proporções entre os valores são mais importantes do que os valores absolutos dos dados. Por exemplo: a contagem $x_{i j}$ depende do total de tags da biblioteca, mas a proporção das tags é um valor muito mais informativo para o estudo da expressão gênica.

Uma composição é um vetor de proporções, como $\left[\frac{1}{15}, \frac{4}{14}, \frac{2}{3}\right]$. A análise de composições tem sido largamente empregada na geologia[22], no estudo de orçamentos familiares[94], na biologia populacional[86], na predição de genes[100] e outras áreas. Usualmente os valores são escritos com a soma normalizada para um, porém qualquer outro valor estritamente positivo pode ser utilizado.

\subsubsection{Composições e o espaço simplex}

Definição 3. Uma composição $\mathbf{x}$ de D partes é um vetor de dimensão D em que cada componente $x_{1}, \cdots, x_{D}$ é positiva e a soma total é 1 .

Nota-se que a restrição na soma torna a composição completamente definida pelas primeiras $D=d+1$ componentes, sendo que a última componente é apenas o valor que falta para interar 1 (eq. 5.7). Portanto, existem duas formas equivalentes para especificar uma composição, com $D$ ou $d$ componentes, e que podem ser utilizadas da maneira que for mais conveniente. 


$$
x_{D}=1-x_{1}-\cdots-x_{d}
$$

O espaço amostral associado às composições é o simplex, que pode ser definido de duas maneiras, dependendo da definição de composição utilizada (definições 4 e 5). Ambas as definições representam os mesmos conjuntos de composições, mudando somente a interpretação geométrica delas (figuras 5.3 e 5.4).

Definição 4. O espaço d-dimensional simplex é definido por:

$$
\mathscr{L}^{d}=\left\{\left(x_{1}, \cdots, x_{d}\right) ; x_{1}>0, \cdots, x_{d}>0 ; x_{1}+\cdots+x_{d}<1\right\}
$$

Definição 5. O espaço d-dimensional simplex encapsulado por um espaço D-dimensional real é definido por:

$$
\mathscr{L}^{d}=\left\{\left(x_{1}, \cdots, x_{D}\right) ; x_{1}>0, \cdots, x_{D}>0 ; x_{1}+\cdots+x_{D}=1\right\}
$$

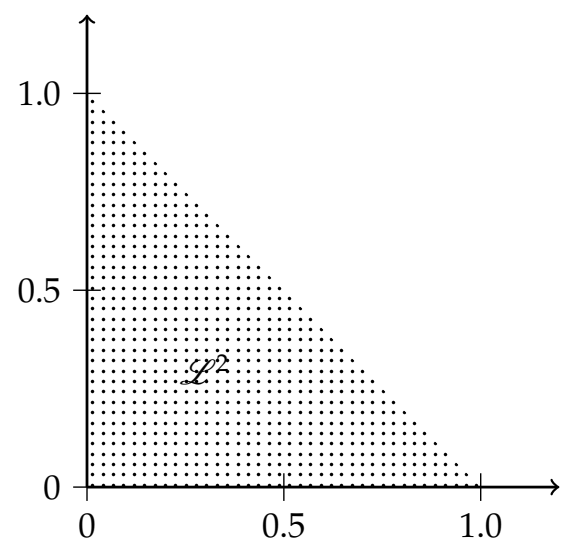

Figura 5.3: $\mathscr{L}^{2}$ representado em $\mathbb{R}^{2}$. 


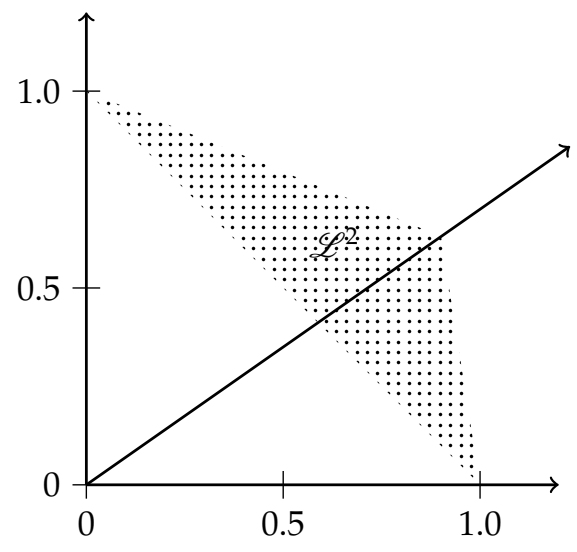

Figura 5.4: $\mathscr{L}^{2}$ representado encapsulado em $\mathbb{R}^{3}$.

\subsubsection{Estrutura de covariância em composições}

Desde o trabalho de Karl Pearson de 1896[78] sobre correlações espúrias, é conhecido o problema de interpretação de correlações entre razões cujos numeradores e denominadores possuem partes em comum, o que torna inadequado o uso de correlações no estudo de dados composicionais.

Naquele trabalho, Pearson mostra que, se as variáveis $w_{1}, w_{2}$ e $w_{3}$ forem independentes, as razões $x_{1}=w_{1} / w_{3}$ e $x_{2}=w_{2} / w_{3}$ têm aproximadamente correlação:

$$
\frac{\alpha_{3}^{2}}{\left[\left(\alpha_{1}^{2}+\alpha_{3}^{2}\right)\left(\alpha_{2}^{2}+\alpha_{3}^{2}\right)\right]^{1 / 2}}
$$

onde $\alpha_{1}, \alpha_{2}, \alpha_{4}$ são os coeficiêntes de variação de $w_{1}, w_{2}, w_{3}$. Tal resultado pode ser estendido para as razões $w_{1} /\left(w_{1}+w_{2}+w_{3}\right)$ e $w_{2} /\left(w_{1}+w_{2}+w_{3}\right)$, que são os componentes da composição. Ou seja, a ausência de correlação da base não implica ausência de correlação na composição.

Outra dificuldade surge da condição de restrição $x_{1}+\cdots+x_{D}=1$, pois

$$
\operatorname{cov}\left(x_{1}, x_{1}+\cdots+x_{D}\right)=0
$$


e portanto

$$
\operatorname{cov}\left(x_{1}, x_{2}\right)+\cdots+\operatorname{cov}\left(x_{1}, x_{d}\right)=-\operatorname{var}\left(x_{1}\right)
$$

Como o lado direito da equação 5.9 é negativo, pelo menos uma das covariâncias tem que ser negativa. Esse resultado indica que é inapropriado o uso da correlação de Pearson como medida de dissimilaridade entre composições.

\subsection{Uma métrica para o espaço simplex}

O espaço simplex é diferente do espaço euclidiano nas operações que podem ser feitas com vetores contidos nele. A operação de translação no espaço euclidiano $\mathbf{x}=\mathbf{a}+\mathbf{t}$ não é válida para o espaço simplex, pois a imagem da operação + pode sair do espaço. A operação equivalente no $d$-simplex é a operação de perturbação [2]. Dados dois vetores $\mathbf{t}, \boldsymbol{\pi} \in S_{d}$, a perturbação de $\pi$ por $\mathbf{t}$ é definida pela equação 5.10 :

$$
\boldsymbol{\pi} \circ \mathbf{t}=\frac{\left(t_{1} \pi_{1}, \cdots, t_{D} \pi_{D}\right)}{t_{1} \pi_{1}+\cdots+t_{D} \pi_{D}}
$$

Assim como é possível definir métricas invariantes quanto à translação no espaço euclidiano, é possível definir uma métrica que seja invariante quanto a perturbações, ou seja:

$$
\Delta(\boldsymbol{\pi} \circ \mathbf{t}, \rho \circ \mathbf{t})=\Delta(\pi, \rho)
$$

Uma outra operação, esta específica ao espaço simplex, é a subcomposição das componentes do $\pi \in S_{d}$. Definida por um conjunto de índices i de tamanho $k \leq D$, ela é dada pela eq. 5.12 .

$$
C(\pi, \mathbf{i})=\left(\pi_{i_{1}}, \cdots, \pi_{i_{k}}\right) /\left(\pi_{i_{1}}+\cdots+\pi_{i_{k}}\right)
$$


É desejável que dois cientistas, um trabalhando com $\pi$ e outro trabalhando com uma subcomposição de $\rho=\operatorname{subc}(\pi, \mathbf{i})$, cheguem às mesmas conclusões sobre as partes em comum de $\pi$ e $\rho$. Esta propriedade é chamada coerência subcomposicional[6]. Por esses motivos, Aitchison propôs uma métrica invariante quanto a perturbações e que preserva a coerência subcomposicional [1], definida como:

$$
\begin{aligned}
\Delta(\pi, \rho) & =\left[\sum_{i=1}^{D}\left\{\log \frac{\pi_{i}}{g(\pi)}-\log \frac{\rho_{i}}{g(\rho)}\right\}^{2}\right]^{1 / 2} \\
g(\pi) & =\left[\prod_{i=1}^{D} \pi_{i}\right]^{1 / D}
\end{aligned}
$$

Note-se que a distância de Aitchison é a distância Euclidiana sobre o vetor $\mathbf{y}=\pi / g(\pi)$, onde $g(\pi)$ é a média geométrica das componentes.

A métrica de Aitchison possui coerência subcomposicional [2], que neste caso significa que, dadas duas composições $\pi^{(1)}$ e $\pi^{(2)}$, e suas respectivas subcomposições $\rho^{(1)}$ e $\rho^{(2)}$ :

$$
\Delta\left(\pi^{(1)}, \pi^{(2)}\right) \geq \Delta\left(\rho^{(1)}, \rho^{(2)}\right)
$$

É possível mostrar de modo relativamente simples que nenhuma das distâncias usualmente aplicadas para agrupamentos de dados de contagem - Manhattan, Euclidiana, distância de Pearson etc. - possui as propriedades específicas para composições.

A coerência de subcomposição pode ser ilustrada pelo seguinte exemplo: sejam duas trinas de genes $\pi^{(1)}$ e $\pi^{(2)}$ com os valores $(0,2 ; 0,7 ; 0,1)$ e $(0,7 ; 0,2 ; 0,1)$. E sejam $\rho^{(1)}$ e $\rho^{(2)}$ as suas respectivas subcomposições, formadas pelos dois primeiros elementos destas trinas. Na tabela abaixo estão mostradas as distância de Aitchison e Euclidiana: 


\begin{tabular}{lrr} 
& Aitchison & Euclidiana \\
\hline \hline$\Delta\left(\pi^{(1)}, \pi^{(2)}\right)$ & 1.7716745 & 0.707106 \\
$\Delta\left(\rho^{(1)}, \rho^{(2)}\right)$ & 1.7716743 & 0.785674
\end{tabular}

Tabela 5.1: Comparação ilustrativa da distância de Aitchison e Euclidiana para duas composições e suas respectivas subcomposições.

Obviamente, se em vez de uma subcomposição, simplesmente se descartasse o terceiro gene, a distância Euclidiana não sofreria variação. Porém, é mais coerente sempre considerar a operação de subcomposição. Os dados de abundância observados experimentalmente decerto são uma subcomposição do transcriptoma, pois não é possível garantir que $D$ seja o número total de transcritos possíveis.

No exemplo anterior, o terceiro gene da trina tem a mesma abundância em $\pi^{(1)} \mathrm{e} \pi^{(2)}$, e removê-lo reduz levemente a distância de Aitchison entre as subcomposição, enquanto que a distância Euclidiana aumenta de forma incoerente esta distância.

Eliminar do conjunto de dados as tags pouco expressas é um procedimento muito comum, por isso é tão importante exigir coerência subcomposicional da métrica adotada.

A distância de Aitchison é usada em Geologia há mais de 20 anos[1, 3, 5]. Entretanto, não existe na literatura nenhuma aplicação desta em Bioinformática, apesar da abundância dos transcritos ser claramente uma subcomposição. Por este motivo, foi desenvolvido um software que realiza o agrupamento hierárquico de dados de contagem em acordo com o arcabouço teórico desenvolvido neste projeto.

\subsection{Implementação}

Optou-se pela linguagem de programação $C$ em razão da necessidade de uma implemen-ta-ção eficiente, e que consumisse uma quantidade de memória compatível com o tamanho dos conjuntos de dados que se pretende analisar. Atualmente, tal programa agrupa hierarquicamente um conjunto de dados, com mais 200 mil etiquetas de SAGE e 87 amostras, em aproximadamente 1 minuto, e utilizando um pouco menos de 360MB de 
memória. Esssa estimativa corresponde a um computador pessoal moderno (Athlon 64 3000). O fato do programa estar em $C$ facilita a sua implantação, pois não é necessário nenhum ambiente ou interpretador de linguagem para que o usuário possa executá-lo em seu computador.

A implementação do programa utilizou como base a biblioteca de agrupamento desenvolvida por Michael de Hoon [37] e a biblioteca de agrupamentos hirárquicos desenvolvida por F. Murtagh[72] $]^{1}$.

Para a funcionalidade de visualização, adaptou-se o código de desenho de árvores filogenéticas do programa TreeView $X$ de Rod Page [76], para que se trabalhasse com as grandes árvores geradas pelo programa de agrupamento hierárquico. O código de desenho também foi modificado para utilizar a biblioteca de gráficos vetoriais Cairo [95], pois ela permite a criação de imagens de alta qualidade em formato PostScript, PDF e imagens bitmap em formato PNG.

O programa de visualização aceita como parâmetro adicional um arquivo com informações extras das bibliotecas. Tal arquivo contém três colunas: a identificação, a classe e a descrição da biblioteca. A descrição é inserida na figura gerada e os ramos da árvore são coloridos segundo as suas classes. Colorir os ramos pode parecer um detalhe pouco relevante, porém trata-se de um recurso visual que facilita a identificação dos padrões de agrupamento das amostras.

É possível utilizar diversos esquemas de classes sem que seja necessário executar novamente o programa de agrupamento, pois é uma etapa muito mais demorada do que a geração da figura.

A escolha das cores dos ramos baseou-se no esquema de cores ColorBREW [51]. A escolha de um bom esquema de cores torna as figuras mais agradáveis à visualização. A figura 5.2 é um exemplo.

O código-fonte destes programas está disponível na URL:

\footnotetext{
${ }^{1}$ Esse é o código da rotina hclust utilizado pelo programa $R$ e também incluso na biblioteca STATLIB
} 
http://www.vision.ime.usp.br/ lvaruzza/simcluster

\subsection{Aplicações}

\subsubsection{Agrupamento hierárquico de bibliotecas de tecidos cerebrais}

Para a avaliação da distância de Aitchison foram utilizados dados reais de expressão gênica de tecidos cerebrais, tanto normais quanto tumorais, obtidos do banco de dados SAGE Genie. A descrição detalhada das bibliotecas utilizadas está disponível em:

http://www.vision.ime.usp.br/ lvaruzza/projeto/liblst.txt

Nas figuras disponíveis no site:

http://www.vision.ime.usp.br/ lvaruzza/simcluster/results_brain.html

Pode-se ver os seguintes resultados qualitativos:

1. As bibliotecas estão, em geral, bem mais agrupadas de acordo com o tipo de tumor;

2. A biblioteca construída a partir de um feto humano não se agrupa com nenhuma outra biblioteca. Isso é esperado, pois acredita-se que o repertório de transcritos neuronais de um feto é extremamente diferente do de um indivíduo adulto;

3. As bibliotecas construídas a partir de linhagens celulares estão quase todas em um mesmo grupo.

\subsubsection{Análise de agrupamento de dados relativos à doença de Alzheimer}

A doença de Alzheimer é a causa mais comum de demência. Ele é uma doença neurodegenerativa e terminal para a qual ainda não existe cura. A doença é caracterizada pela formação de placas senis e emaranhados neurofibrilares[74]. Três isoformas da apolipopreoína E (apoE2, E3 e E4) estão associados com o risco da doênça. Sabe-se que possuir o alelo APOE2 reduz o risco da doênça em relação ao alelo 3, enquanto que o alelo 4 aumenta 
o risco[28]. Para estudar a influência do gene APOE, Pu-Ting $\mathrm{Xu}$ et al[96] produziram 3 bibliotecas de SAGE para pacientes diagnosticados com a doença, com os seguintes genótipos: APOE3/3, APOE3/4 e APOE4/4, e uma biblioteca para um paciente normal com o alelo APOE3/3.

O programa simcluster foi utilizado para análisar as bibliotecas de Alzheimer. Os autovalores do PCA calculado pelo programa simpca estão na tabela 5.2. O menor número de agrupamentos que representam aproximadamente $90 \%$ variância é 3, com representação de $89,1 \%$, a segunda melhor opção é dividir os dados em 2 agrupamentos.

\begin{tabular}{rrr}
$\#$ & $V$ & $V_{\text {acumulado }}$ \\
\hline 1 & $62,7 \%$ & $62,8 \%$ \\
2 & $14,6 \%$ & $77,4 \%$ \\
3 & $11,8 \%$ & $89,1 \%$ \\
4 & $10,8 \%$ & $100 \%$
\end{tabular}

Tabela 5.2: Variância representada por cada autovetor.

Os valores de expressão das bibliotecas foram projetados nas duas e três primeiras componentes principais (fig. 5.5). Vê-se claramente que as bibliotecas N33 AD33 estão próximas, e que a biblioteca AD44 é mais próxima destas do que a biblioteca AD34.

Utilizando o simpart para particionar o conjunto de dados em 2 e 3 agrupamentos através do algoritmo de k-medóides. Na tabela 5.3 estão descritos os grupos encontrados, e a soma das distâncias dos membros ao centro de cada grupo $G_{E}$. Comparando essas medidas para 2 e 3 grupos, conclui-se que a separação em três grupos gera agrupamentos mais coesos.

\begin{tabular}{ccc|cc}
$G_{3}(1)$ & $G_{3}(2)$ & $G_{3}(3)$ & \multicolumn{1}{|c}{$G_{2}(1)$} & $G_{2}(2)$ \\
\hline $\mathrm{N} 33, \mathrm{AD} 33$ & $\mathrm{AD} 34$ & $\mathrm{AD} 44$ & $\mathrm{AD} 44, \mathrm{~N} 33, \mathrm{AD} 33$ & $\mathrm{AD} 34$ \\
$G_{E}=0,308$ & & & $G_{E}=0,645$ &
\end{tabular}

Tabela 5.3: Agrupamentos obtidos pelo agoritimo de 3-medóides e 2-medóides.

Na figura 5.6 estão os agrupamentos hierárquicos feitos com as distâncias de Aitchison e Pearson, e com os métodos de ligação completo, média, singular e centróide. Novamente existe uma indefinição quanto ao número de agrupamentos, mas quando existem 3 grupos, 

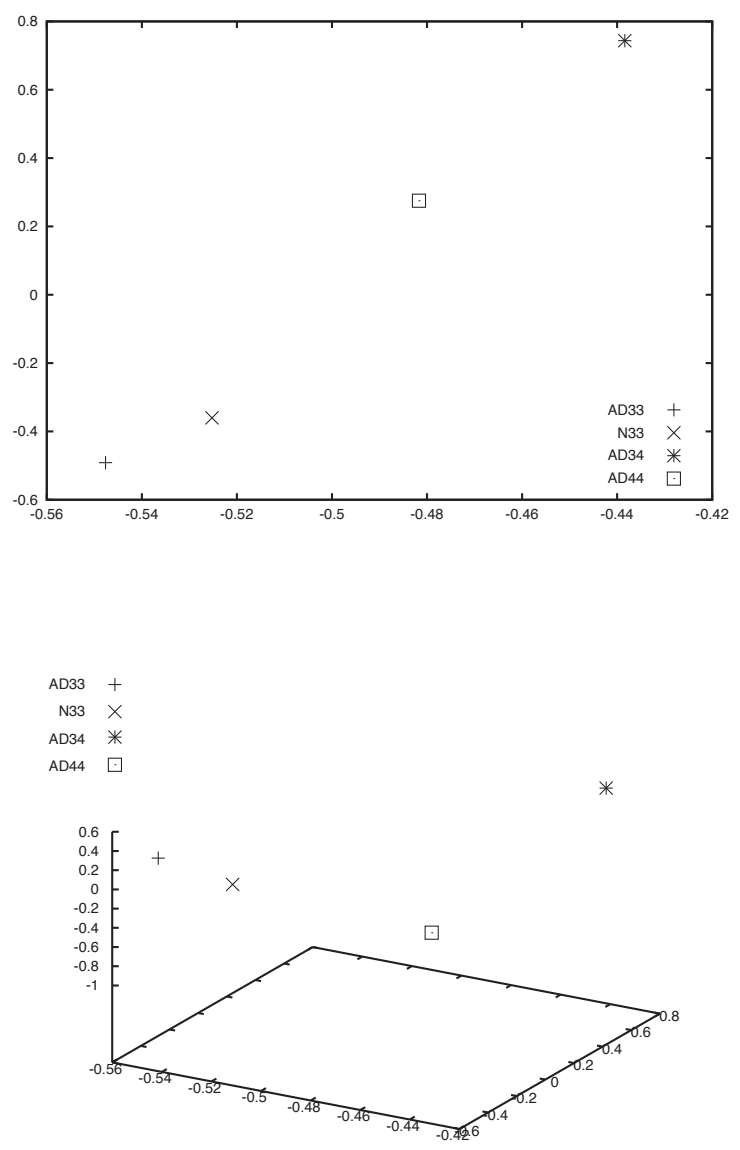

Figura 5.5: Projeção das bibliotecas nas primeiras 2 e 3 componentes principais.

a biblioteca AD34 é a mais distante.

Todas as análises de agrupamento executadas indicam claramente que as bibliotecas com alelos 3/3 são as mais similares. Elas também indicam, de maneira um pouco menos contundente, que a biblioteca AD 3/4 é a mais distante, e que a biblioteca AD 4/4 está entre esses dois extremos. As análises não indicam de maneira conclusiva se existem dois ou três agrupamentos.

Mesmo para um número pequeno de amostras, as análises sugerem uma hipótese: a presença do alelo 4 altera de maneira significativa a expressão dos genes, mas a presença do segundo alelo 4 aparenta ter um efeito mais fraco na mudança dos valores de expressão. 


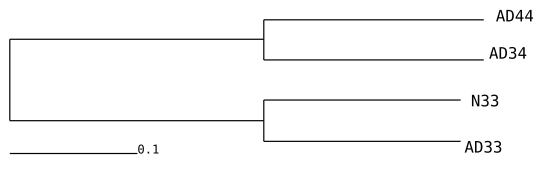

Aitchison Completo

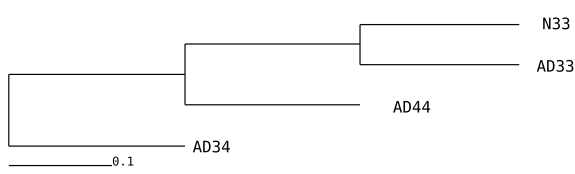

Aitchison Singular

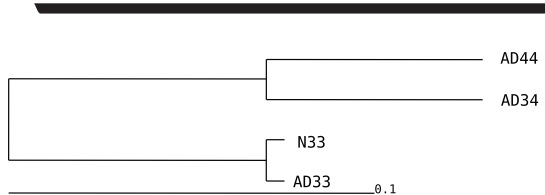

Peasron Completo

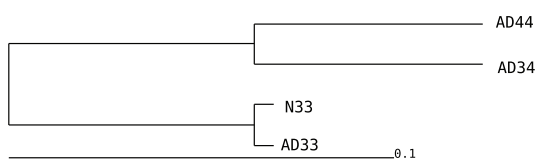

Pearson Singular

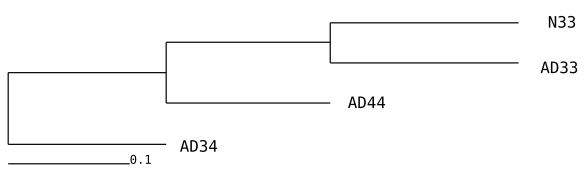

Aitchison Centroide

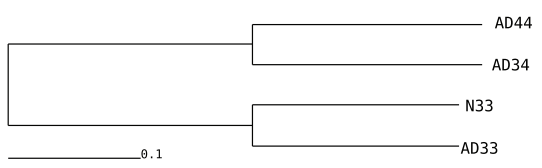

Aitchison Média

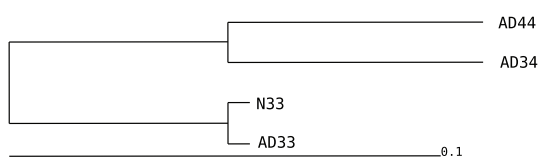

Pearson Centroide

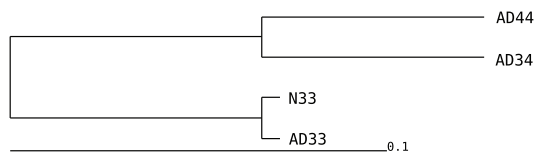

Pearson Média

Figura 5.6: Agrupamento Hierárquico das bibliotecas de Doença de Alzheimer. 


\subsubsection{Agrupamento de dados com tags pré-selecionadas}

O objetivo deste exemplo é mostrar que o método proposto é capaz de identificar agrupamentos significativos mesmo após a uma etapa de pré-seleção de tags. ChabardesGaronne et al[23] criaram um conjunto de dados de tecidos de diferentes regiões do rim, com 773 tags que eles consideraram diferencialmente expressas. Os códigos das regiões estudadas são Glom: Glomerulus, PCT: proximal convoluted tubes, PST: proximal straight tubule, MTAL: medullary thick ascending limb of Henle's loop, CTAL: cortical thick ascending limb of Henle's loop, CCD: cortical collecting duct, OMCD: outer medullary collecting duct, DCT: distal convoluted tubule.

Nas figuras 5.7, 5.8 e 5.9 vê-se respectivamente o agrupamento das bibliotecas com a distância de Aitchison, Pearson e Euclides. Somente a distância de Aitchison é capaz de chegar ao mesmo dendrograma do artigo[23, fig. 3].

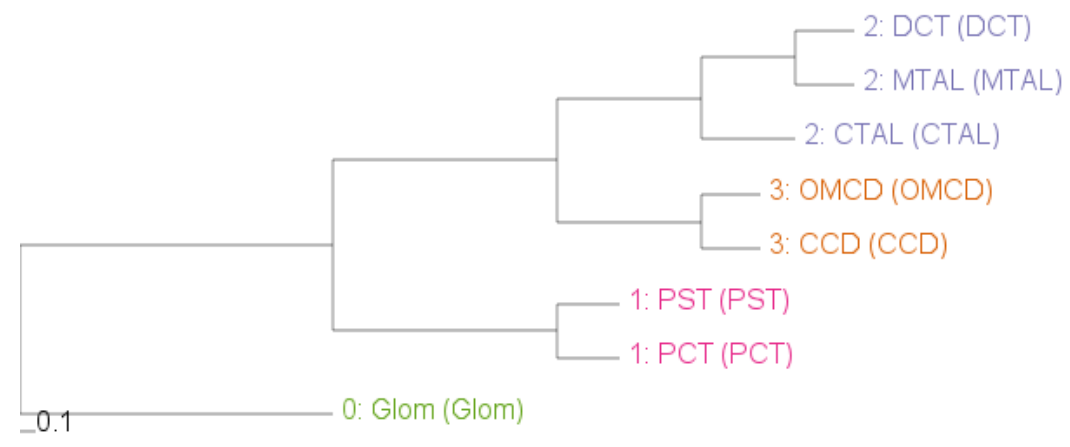

Figura 5.7: Agrupamentos de bibliotecas de tecidos de rim. Distância de Aitchison.

\subsubsection{Northern Digital}

O objetivo deste exemplo é mostrar que o método proposto é capaz de agrupar dados gerados por Northern Digital. O conjunto de dados é do ciclo de desenolvimento do fungo Blastocladiella emersonii, Ribichich et al[81] produziram 9 bibliotecas dos estágios descritos por Lovett[62]. As fases de desenvolvimento são: Zoosporito (ZSP); Germinação (em 30, 


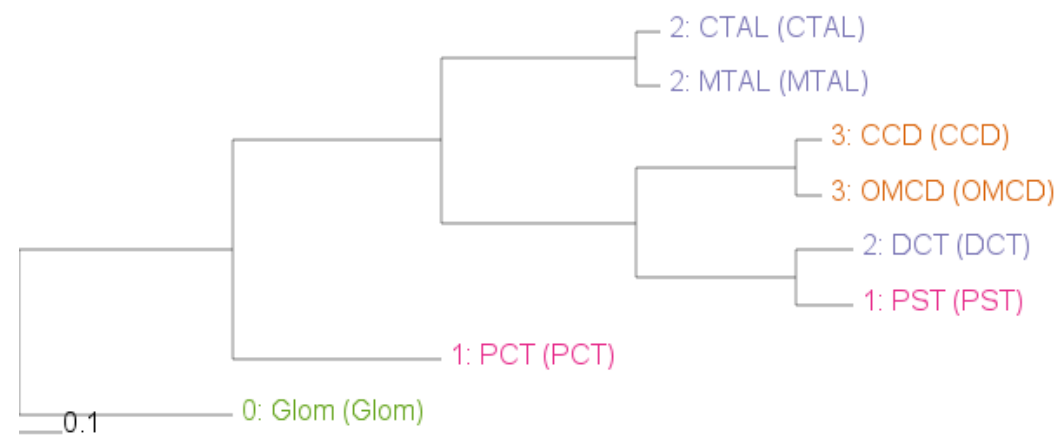

Figura 5.8: Agrupamentos de bibliotecas de tecidos de rim. Distância de Pearson.

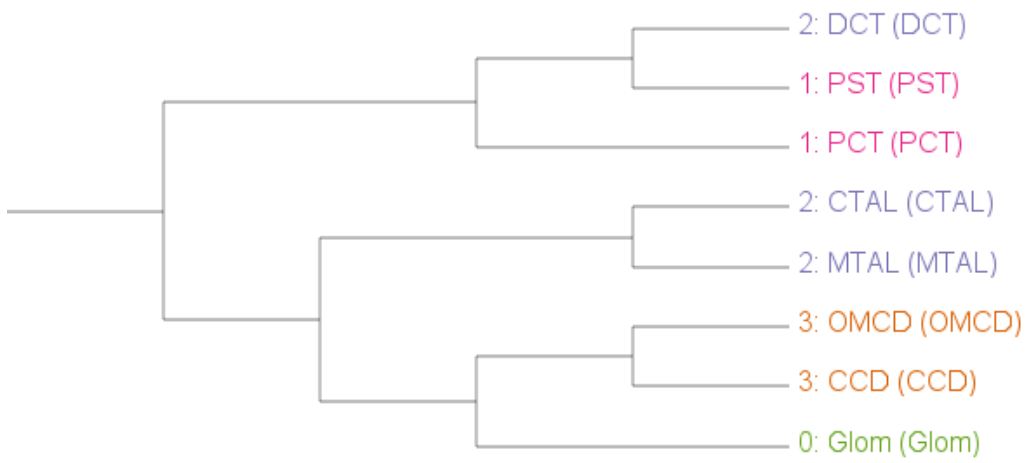

Figura 5.9: Agrupamentos de bibliotecas de tecidos de rim. Distância de Euclides.

60, 90 e 120 minutos indicados por G30, G60, G90 e G120, respectivamente); Esporulação (em 30, 60, 90 e 120 minutos como E30, E60, E90 e E120 respectivamente). O ciclo está ilustrado na figura 5.10 .

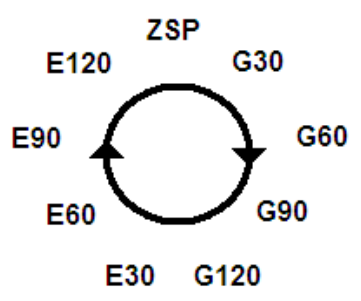

Figura 5.10: Estágios de desenvolvimento de B. emersonii.

Nas figuras 5.11, 5.12 e 5.13 vê-se respectivamente o agrupamento das bibliotecas com a distância de Aitchison, Pearson e Euclides. 


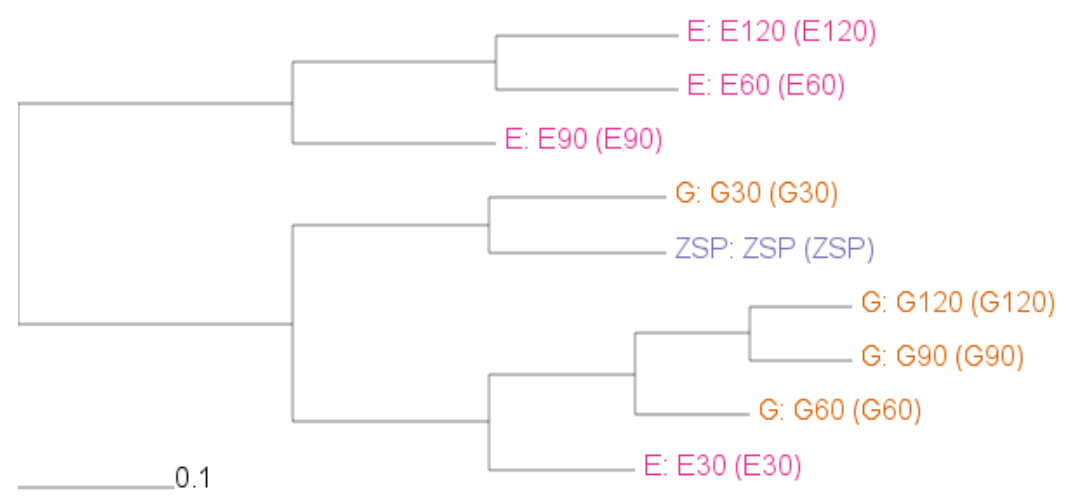

Figura 5.11: Agrupamentos de bibliotecas dos estágios de desenvolvimento de B. emersonii. Distância de Aitchison.

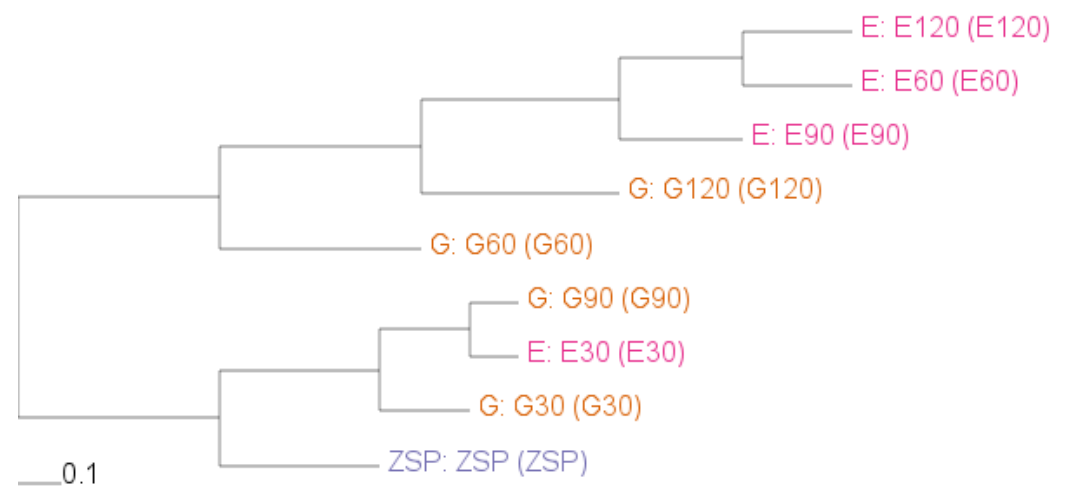

Figura 5.12: Agrupamentos de bibliotecas dos estágios de desenvolvimento de B. emersonii. Distância de Pearson.

Nota-se que o método proposto conseguiu agrupar estágios consecutivos de maneira melhor que os outros métodos. Em particular, ele colocou no mesmo grupo a fase de zoosporito ZSP e a primeira fase de geminação G30, que acredita-se ser mais próxima da fase de germinação do que da fase de esporulação. 


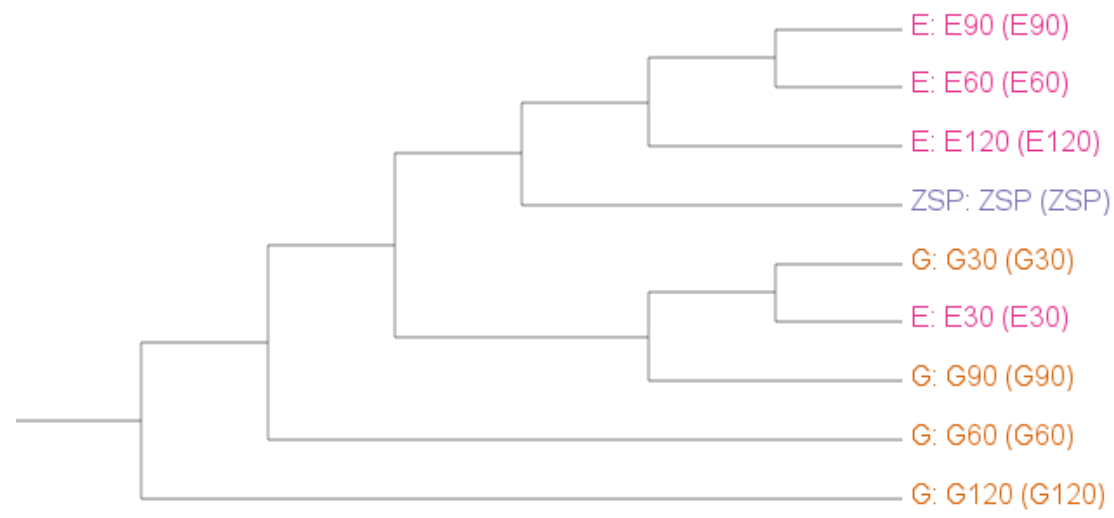

Figura 5.13: Agrupamentos de bibliotecas dos estágios de desenvolvimento de B. emersonii. Distância de Euclides. 


\section{Capítulo 6}

\section{Considerações Finais}

\subsection{Conclusão}

Nesta tese foram propostos e implementados dois novos métodos para identificar tags diferencialmente expressas em bibliotecas digitais de expressão gênica (chamados de Kemp e Basu). Também foi proposto o uso da distância de Aitchison na análise de agrupamento destas bibliotecas, e para que a comunidade de biologia molecular possa facilmente utiliza-la em seus conjuntos de dados, a distância foi implementado em um programa chamado Simcluster. Com esses métodos buscou-se analisar as bibliotecas digitais de diversos ângulos: o simcluster busca padrões de agrupamentos analisando as bibliotecas como um todo, enquanto que os testes de significância propostos, Kemp e Basu, analisam as bibliotecas tag-a-tag, buscando por tags diferencialmente expressas.

O Simcluster é um adição ao ferramental disponível para a análise de dados de contagem. É também, uma contribuição para a bioinformática pois traz para a área métodos desenvolvidos originalmente no âmbito da estatística aplicada à geologia.

Em relação à detecção de tags diferencialmente expressas, os testes propostos são uma alternativa exata, tanto freqüêntista quanto bayesiana, aos métodos existentes. No passado os testes de hipótese eram limitados pela capacidade computacional disponível, 
e muitas vezes era preciso trocar precisão por facilidade numérica através do uso de resultados assintóticos. Atualmente, com o avanço dos computadores, é possível fazer o cálculo de níveis de significância exatos para diversos modelos estatísticos. Um teste exata é algo muito importante na análise de expressão gênica, pois mutas tags relevantes tem uma baixa expressão, com a contagem total inferior à duas dezenas. O teste Bayesiano desenvolvido, chamado de Basu, foi construído no arcabouço do FBST (Full Bayesian Statistical Test), que é um método Bayesiano geral para a construção de testes de hipóteses. Já o teste frequentista Kemp foi construído utilizando a definição de pontos mais extremos. Como mostrado na seção 4.3, os valores médios dos níveis de significância, $p$-valor para o Kemp e e-valor para o Basu, estão ligados por uma função conhecida. Esse resultado é uma indicação da adequação dos testes, pois apesar de terem sido construídos com premissas completamente diferentes ambos concordam entre si.

Na seção 3.4.5 o Kemp é comparado com o teste do $\chi^{2}$ e mostra-se que para tags com alta expressão, ambos os testes geram níveis de significância com valores muito próximos, porém, para tags pouco expressas há um desacordo nos níveis de significância calculados. Ou seja, para as tags para a qual o $\chi^{2}$ é valido, os dois testes são equivalentes, porém, para as tags na qual o $\chi^{2}$ não é adequado o Kemp produz resultados diferentes, como o Kemp não utiliza nenhum resultado que depende da contagem das tags, concluímos que ele é mais adequado que o $\chi^{2}$. De fato, as tags de alta expressão não são mais importantes do que as de baixa expressão, inclusive muitos genes de alta expressão são os chamados housekeeping, de pouco interesse em estudos de diferença de expressão, enquanto que muitos genes importantes apresentam uma expressão baixa[91]. Julgar todas as tags, independentemente da sua contagem total, de maneira justa é o principal resultado dos testes propostos. Para resolver o problema do $\chi^{2}$ aplicadao as tags de baixa contagem, alguém poderia sugerir utiliza-lo combinado com um teste exato para a tags de baixa expressão, ainda assim as tags não estariam sendo testadas de maneira apropriada, pois uma parte seria avaliada segundo um critério, e outra parte segundo outro critério. 
Também no sentido de julgar todas as tags de maneira justa, foi desenvolvido um método para calcular automaticamente o nível crítico levando em conta a contagem total de cada tag. Se o nível crítico, o mínimo do erro do tipo I, é fixado, o erro do tipo II decresce drasticamente quando a contagem aumenta, e portanto, fica difícil aceitar a hipótese nula para as tags de alta expressão, ou rejeitá-la para as tags de baixa expressão. Por exemplo, comparando a expressão de duas bibliotecas hipotéticas com 10mil tags cada, uma tag com contagens 7 e 21, respectivamente, teria um p-valor de 0.013. Entretanto, uma tag com contagens 10 e 30 resultaria em um p-valor de 0.002. Considerando um curte de 0.01, a primeira tag seria considerada como igualmente expressas nas duas bibliotecas, enquanto que a segunda seria interpretada como sendo diferencialmente expressa. No nosso método o nível crítico é aquele que minimiza uma combinação linear dos erros do tipo I ( $\alpha$ ) e do tipo II $(\beta)$. Com essa abordagem tag-customizada ambas as tags do exemplo acima seriam consideradas diferencialmente expressas, pois os seus níveis críticos seriam respectivamente 0.015 e 0.013 .

Por levar em conta a natureza das bibliotecas de contagem, seja olhando para a geometria do espaço paramétrico ou construindo testes exatos, acreditamos que o presente trabalho representa um aperfeiçoamento aos métodos existentes de análise desses dados.

O código fonte de todos os programas desenvolvidos esta disponível gratuitamente sob licença GPL nos seguintes sites: http://code.google.com/p/kempbasu/ e http: //www.vision.ime.usp.br/ lvaruzza/simcluster.

\subsection{Outros trabalhos}

Durante o doutorado me envolvi em outros trabalhos. Trabalhei com o Prof. Arthur Gruber do ICB e Alan M. Durham do IME na criação de um Pipeline Genérico para processamento de seqüência, trabalho este que gerou um artigo na revista Bioinformatics[43]. Eu colaborei também na análise dos dados de EST e SAGE de Eimeria sp. gerados pelo 
grupo do Prof. Gruber, os resultados desses trabalhos foram apresentados no "IXth International Coccidiosis Conference" em Foz do Iguaçu (2005).

Além dos programas descritos nesta tese, desenvolvi uma biblioteca para geração de valores aleatórios segundo algumas distribuições de probabilidade conhecidas para Common Lisp ${ }^{1}$.

\subsection{Trabalhos Futuros}

O método Kemp implementa completamente um procedimento de decisão pois ele provém um nível de significância e um nível crítico, porém, o método Basu não calcula o corte mais apropriado. Para esta tarefa, pretendemos no futuro próximo desenvolver o cálculo do nível crítico baseados na teoria de decisão, como descritos por [21].

\footnotetext{
${ }^{1}$ cl-randits: http://code.google.com/p/cl-randist/
} 


\section{Lista de Tabelas}

1.1 Lista dos aminoácidos e seus respectivos símbolos. . . . . . . . . . . . . . 13

1.2 Código Genético . . . . . . . . . . . . . . . . . . . . . . . . . 14

2.1 Resumo de alguns conjuntos de dados de SAGE e Long SAGE . . . . . . . 22

2.2 Quartis, média e mediana da variável y . . . . . . . . . . . . 22

2.3 Exemplo de matriz de dados de contagem . . . . . . . . . . . . . . . 23

3.1 Coeficiêntes da função de corte que minimiza $4 \alpha+\beta \ldots$. . . . . . . . . 39

3.2 Coeficiêntes da função de corte que minimiza $\alpha+\beta \ldots 39$

3.3 Tabela de contingência para teste de diferenciação . . . . . . . . . . . . . 43

5.1 Comparação ilustrativa da distância de Aitchison e Euclidiana para duas composições e suas respectivas subcomposições. . . . . . . . . . . . . . . . . 64

5.2 Variância representada por cada autovetor. . . . . . . . . . . . . . 67

5.3 Agrupamentos obtidos pelo agoritimo de 3-medóides e 2-medóides. . . . . 67 


\section{Lista de Figuras}

1.1 Fluxo de informação na célula do DNA até a proteína. . . . . . . . . . . . . 14

1.2 Via metabólica do ciclo do ácido cítrico. Fonte: KEGG. . . . . . . . . . . 16

3.1 Ilustração das hipóteses nula e alternativa . . . . . . . . . . . . . . . . . 31

3.2 Ilustração das nova formulação das hipóteses nula e alternativa . . . . . . 32

3.3 Dedução do máximo da multinomial de 3 classes . . . . . . . . . . . . . . . . 34

3.4 Algoritmo para o cálculo do p-valor pelo método de Monte Carlo. Parâmetros de entrada: $\mathbf{X}$ : Vetor com as contagens de uma tag, $\mathbf{N}$ vetor com o número total de tags nas bibliotecas e runs número de amostragens para o cálculo

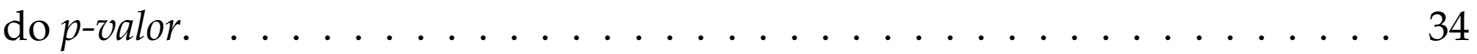

3.5 Gráfico dilog com os valores de corte simulados e a função do nível crítico para comparação de duas bibiliotecas . . . . . . . . . . . . . . 37

3.6 Gráfico dilog com os valores de corte simulados e a função do nível crítico para comparação de cinco bibiliotecas . . . . . . . . . . . . . 38

3.7 P-valor proposto versus o p-valor calculado para tags com expressão alta . . 45

3.8 P-valor proposto versus o p-valor calculado para tags com expressão baixa . 46

4.1 Ilustração do FBST . . . . . . . . . . . . . . . . . . . . . . . . . 49

4.2 p-valor versus média ponderada do e-valor para o conjunto de dados de Alzheimer . . . . . . . . . . . . . . . . . . . 51

4.3 Ajuste da função de ligação para os dados de Alzheimer . . . . . . . . . . 51 
4.4 -valor versus média ponderada do e-valor para o conjunto de dados de pele 52

4.5 Ajuste da função de ligação para os dados de Alzheimer . . . . . . . . . . . 52

5.1 Exemplos de agrupamento hierárquico. . . . . . . . . . . . . . . 54

5.2 Exemplo de agrupamento em dados públicos de SAGE. . . . . . . . . . . . . 57

$5.3 \mathscr{L}^{2}$ representado em $\mathbb{R}^{2} \ldots \ldots \ldots \ldots$. . . . . . . . . . . . 60

$5.4 \mathscr{L}^{2}$ representado encapsulado em $\mathbb{R}^{3} \ldots \ldots \ldots$. . . . . . . . . . . 61

5.5 Projeção das bibliotecas nas primeiras 2 e 3 componentes principais. . . . 68

5.6 Agrupamento Hierárquico das bibliotecas de Doença de Alzheimer. . . . . . 69

5.7 Agrupamentos de bibliotecas de tecidos de rim. Distância de Aitchison. . 70

5.8 Agrupamentos de bibliotecas de tecidos de rim. Distância de Pearson. . . 71

5.9 Agrupamentos de bibliotecas de tecidos de rim. Distância de Euclides. . . . 71

5.10 Estágios de desenvolvimento de B. emersonii. . . . . . . . . . . . . . . 71

5.11 Agrupamentos de bibliotecas dos estágios de desenvolvimento de B. emersonii. Distância de Aitchison. . . . . . . . . . . . . . . . . . . 72

5.12 Agrupamentos de bibliotecas dos estágios de desenvolvimento de B. emersonii. Distância de Pearson. . . . . . . . . . . . . . . . . . . . . . 72

5.13 Agrupamentos de bibliotecas dos estágios de desenvolvimento de B. emersonii. Distância de Euclides. . . . . . . . . . . . . . . . . . . 73 


\section{Referências Bibliográficas}

[1] J. Aitchison. Principal component analysis of compositional data. Biometrika, 70(1):57, 1983.

[2] J. Aitchison. The Statistical Annalysis of Compositional Data. Monographs on Statistics and Applied Probability. Chapman and Hall, London, 1986.

[3] J. Aitchison. On criteria for measures of compositional difference. Mathematical Geology, 24(4):365 379, May 1992.

[4] J. Aitchison. The Statistical Annalysis of Compositional Data, chapter 6, pages 126-128. Blackburn Press, Boston, 2003.

[5] J. Aitchison, C. Barceló-Vidal, J. Martín-Fernández, and V. Pawlowsky-Glahn. Logratio Analysis and Compositional Distance. Mathematical Geology, 32(3):271-275, 2000.

[6] J. Aitchison and J. J. Egozcue. Compositional data analysis: Where are we and where should we be heading? Mathematical Geology, 37(7), 2005.

[7] V. Akmaev. Correction of sequence-based artifacts in serial analysis of gene expression. Bioinformatics, 20(8):1254-1263, 2004.

[8] S. Altschul, W. Gish, W. Miller, E. Myers, and D. Lipman. Basic local alignment search tool. J. Mol. Biol, 215(3):403-410, 1990.

[9] M. Ashburner, C. Ball, J. Blake, D. Botstein, H. Butler, J. Cherry, A. Davis, K. Dolinski, S. Dwight, J. Eppig, et al. Gene ontology: tool for the unification of biology. The Gene Ontology Consortium. Nature Genetics, 25(1):25-9, 2000.

[10] S. Audic and J. M. Claverie. The significance of digital gene expression profiles. Genome Res., 7(10):98695, Oct 1997. 
[11] O. T. Avery, C. M. MacLeod, and M. McCarty. Induction of transformation by a desoxyribonucleic acid fraction isolated from pneumococcus type III. J. Exp. Med., 79:137-158, 1944.

[12] K. Baggerly, L. Deng, J. Morris, and C. Aldaz. Overdispersed logistic regression for SAGE: modelling multiple groups and covariates. BMC Bioinformatics, 5:144, Oct 2004.

[13] K. A. Baggerly, L. Deng, J. S. Morris, and C. M. Aldaz. Differential expression in SAGE: accounting for normal between-library variation. Bioinformatics, 19(12):1477-83, Aug 2003.

[14] D. Basu. On the elimination of nuisance parameters. J. Am. Stat. Assoc., 72(358):355-366, 1977.

[15] T. Beissbarth. Statistical modeling of sequencing errors in sage libraries. Bioinformatics, 20(suppl 1):i31-i39, Aug 2004.

[16] J. Berkson. Some difficulties of interpretation encountered in the application of the chi-square test. J. Am. Stat. Assoc., 33(203):526-536, 1938.

[17] S. E. Brenner, M. Johnson, J. Bridgham, G. Golda, D. Lloyd, D. Johnson, S. Luo, S. McCurdy, M. Foy, M. Ewan, et al. Gene expression analysis by massively parallel signature sequencing (MPSS) on microbead arrays. Nature Biotechnology, 18:630-634, 2000.

[18] D. Brett, H. Pospisil, J. Valcarcel, J. Reich, and P. Bork. Alternative splicing and genome complexity. Nature Genetics, 30(1):29-30, 2002.

[19] T. Brown, editor. Genomes 3. Garland Science, London, 2006.

[20] L. Cai, H. Huang, S. Blackshaw, J. S. Liu, C. Cepko, and W. H. Wong. Clustering analysis of SAGE data using a Poisson approach. Genome Biol., 5(7):R51, 2004.

[21] J. M. S. Carlos A de B Pereira and S. Wechsler. Can a Significance Test be Genuinely Bayesian? Bayesian Analysis, 3, 2008.

[22] P. Carr. Distinction between Permian and post-Permian igneous rocks in the southern Sydney Basin, New South Wales, on the basis of major-element geochemistry. Mathematical Geology, 13(3):193-200, 1981.

[23] D. Chabardes-Garonne, A. Mejean, J. Aude, L. Cheval, A. Di Stefano, M. Gaillard, M. Imbert-Teboul, M. Wittner, C. Balian, V. Anthouard, et al. A panoramic view of gene expression in the human kidney. P. Natl. Acad. Sci. USA, 100(23):13710, 2003. 
[24] H. Chen, M. Centola, S. Altschul, and H. Metzger. Characterization of Gene Expression in Resting and Activated Mast Cells. J. Exp. Med., 188(9):1657-1668, 1998.

[25] D. Chin, G. Boyle, R. Williams, K. Ferguson, N. Pandeya, J. Pedley, C. Campbell, D. Theile, P. Parsons, and W. Coman. Novel markers for poor prognosis in head and neck cancer. Int. J. Cancer, 113(5):789797, 2005.

[26] W. G. Cochran. The $\chi^{2}$ test of goodness of fit. Ann. Math. Stat., 23(3):315-345, 1952.

[27] J. Colinge and G. Feger. Detecting the impact of sequencing errors on SAGE data. Bioinformatics, 17(9):840-842, 2001.

[28] W. Corber, D. Checkland, and M. Silberfeld. Assessment of mental capacity. Humane Medicine, 10:40-43, 1994.

[29] Cormen, T.H. and Leiserson, C.E. and Rivest, R.L. and others. Introduction to Algorithms. 2nd, chapter 11. MIT Press, Cambridge, 2001.

[30] D. Cox. Partial likelihood. Biometrika, 62(2):269-276, 1975.

[31] D. Cox and D. Hinkley. Theoretical Statistics. Chapman \& Hall/CRC, Boca Raton, 1979.

[32] F. Crick. The genetic code-yesterday, today and tomorrow. Cold Spring Harbor Symp. Quant. Biol, 31:3-9, 1966.

[33] R. Dahm. Friedrich Miescher and the discovery of DNA. Developmental Biology, 278(2):274-288, 2005.

[34] C. Darwin and J. Carroll. On the Origin of Species. Broadview Press, 2003.

[35] C. S. Davis. The computer generation of multinomial random variates. Comput. Stat. Data An., 16(2):205-217, 1993.

[36] C. A. de Bragança Pereira and J. M. Stern. Evidence and credibility: Full bayesian significance test for precise hypotheses. Entropy, 1(4):99-110, 1999.

[37] M. de Hoon, S. Imoto, J. Nolan, and S. Miyano. Open source clustering software. Bioinformatics, 20:9, 2004.

[38] M. H. DeGroot. Probability and statistics. Addison-Wesley, Boston, 1986. 
[39] A. P. Dempster. The direct use of likelihood for significance testing. Stat. Comput., 7(4):247-252, Nov 1997.

[40] C. Ding and X. He. K-means clustering via principal component analysis. ACM International Conference Proceeding Series, 2004.

[41] S. Draghici, P. Khatri, A. Eklund, and Z. Szallasi. Reliability and reproducibility issues in DNA microarray measurements. Trends in Genetics, 22(2):101-109, 2006.

[42] Q. Du, V. Faber, and M. Gunzburger. Centroidal Voronoi Tessellations: Applications and Algorithms. SIAM Review, 41:637, 1999.

[43] A. Durham, A. Kashiwabara, F. Matsunaga, P. Ahagon, F. Rainone, L. Varuzza, and A. Gruber. Egene: a configurable pipeline generation system for automated sequence analysis. Bioinformatics, 21(12):2812-2813, 2005.

[44] M. M. et al. Genome sequencing in microfabricated high-density picolitre reactors. Nature, 437(7057):376-380, Sep 2005.

[45] B. Everitt, S. Landau, and M. Leese. Cluster Analyses. A Hodder Arnold Publication, London, 2001.

[46] W. Flemming. Zellsubstanz, Kern und Zelltheilung. Vogel, 1882.

[47] I. J. Good, T. N. Gover, and G. J. Mitchell. Exact distributions for $\chi^{2}$ and for the likelihood-ratio statistic for the equiprobable multinomial distribution. J. Am. Stat. Assoc., 65(329):267-283, 1970.

[48] B. Gough. GNU Scientific Library Reference Manual. Network Theory Ltd., 2003.

[49] L. D. Greller and F. L. Tobin. Detecting selective expression of genes and proteins. Genome Res., 9(3):282-96, Mar 1999.

[50] A. Griffiths et al. Introduction to Genetic Analysis, chapter 3. WH Freeman, New York, 1996.

[51] M. Harrower and C. Brewer. Colorbrewer. org: An online tool for selecting colour schemes for maps. The Cartographic Journal, 40(1):27-37, 2003.

[52] C. Heid, J. Stevens, K. Livak, and P. Williams. Real time quantitative PCR. Genome Res., 6:986-994, Oct 1996. 
[53] A. Hershey and M. Chase. Independent functions of viral protein and nucleic acid in growth of bacteriophage. The Journal of General Physiology, 36(1):39-56, 1952.

[54] L. Kaufman and P. J. Rousseeuw. Finding groups in data. Wiley, New York, 1990.

[55] O. Kempthore. Of what use are tests of significance and tests of hypothesis. Communications in Statistics-Theory and Methods, 5(8):763-777, 1976.

[56] O. Kempthorn. Statistical Papers in Honor of G. W. Snedecor, chapter Theories of inference and data analysis, pages 167-191. Iowa State University, Ames, 1972.

[57] K. Koehler and K. Larntz. An empirical investigation of goodness-of-fit statistics for sparse multinomials. J. Am. Stat. Assoc., 75(370):336-344, 1980.

[58] A. Lal, A. Lash, S. F. Altschul, V. E. Velculescu, L. Zhang, R. E. McLendon, M. A. Marra, C. Prange, P. J. Morin, K. Polyak, N. Papadopoulos, B. Vogelstein, K. W. Kinzler, R. Strausberg, and G. J. Riggins. A public database for gene expression in human cancers. Cancer Res, 59(21):5403-7, Nov 1999.

[59] P. Liang. SAGE Genie: A suite with panoramic view of gene expression. P. Natl. Acad. Sci. USA, 99(18):11547, 2002.

[60] D. Lindley. The bayesian analysis of contingency tables. Ann. Math. Stat., pages 1622-1643, Dec 1964.

[61] D. J. Lockhart and E. A. Winzeler. Genomics, gene expression and DNA arrays. Nature, 405(6788):827$836,2000$.

[62] J. Lovett. Growth and differentiation of the water mold Blastocladiella emersonii: cytodifferentiation and the role of ribonucleic acid and protein synthesis. Bacteriological Reviews, 39(4):345, 1975.

[63] J. Lu, J. K. Tomfohr, and T. B. Kepler. Identifying differential expression in multiple sage libraries: an overdispersed log-linear model approach. BMC Bioinformatics, 6:165, Jun 2005.

[64] J. MacQueen. Some methods for classification and analysis of multivariate observations. Proceedings of the Fifth Berkeley Symposium on Mathematical Statistics and Probability, 1(281-297):14, 1967.

[65] E. Mardis. The impact of next-generation sequencing technology on genetics. Trends in Genetics, 24(3):133-141, 2008. 
[66] M. Matsumoto and T. Nishimura. Mersenne Twister: A 623-Dimensionally Equidistributed Uniform Pseudo-Random Number Generator. ACM Transactions on Modeling and Computer Simulation, 8(1):330, 1998.

[67] J. Matthaei, O. Jones, R. Martin, and M. Nirenberg. Characteristics and Composition of RNA Coding Units. P. Natl. Acad. Sci. USA, 48(4):666-677, 1962.

[68] J. Matthaei and M. Nirenberg. Characteristics and Stabilization of DNA ase-Sensitive Protein Synthesis in E. coli Extracts. P. Natl. Acad. Sci. USA, 47(10):1580-1588, 1961.

[69] G. Mendel. Experiments in Plant Hybridisation. Harvard University Press, Cambridge, 1965.

[70] A. Miyamoto, R. Lau, P. Hein, J. Shipley, and G. Weinmaster. Microfibrillar Proteins MAGP-1 and MAGP-2 Induce Notch1 Extracellular Domain Dissociation and Receptor Activation. Journal of Biological Chemistry, 281(15):10089, 2006.

[71] F. Mueller. Pthreads Library Interface. Rapport technique, Florida State University, Department of Computer Science, USA, Juillet, 1995.

[72] F. Murtagh. Multidimensional clustering algorithms. Compstat Lectures. Physika Verlag, Vienna, 1985.

[73] S. Nam, S. Lee, S. Lee, S. Shin, and T. Park. Bayesian Hierarchical Models for Serial Analysis of Gene Expression. Lecture Notes in Computer Science, 4316:29, 2006.

[74] O. of Communications and P. Liaison. Ninds alzheimer's disease information page, June 2008. http://www.ninds.nih.gov/disorders/alzheimersdisease/alzheimersdisease.htm.

[75] K. Okubo, N. Hori, R. Matoba, T. Niiyama, A. Fukushima, Y. Kojima, and K. Matsubara. Large scale cDNA sequencing for analysis of quantitative and qualitative aspects of gene expression. Nature Genetics, 2(3):173-179, 1992.

[76] R. Page. Treeview x, 2006. http://darwin.zoology.gla.ac.uk/ rpage/treeviewx/.

[77] P. Parameswaran, R. Jalili, L. Tao, S. Shokralla, B. Gharizadeh, M. Ronaghi, and A. Fire. A pyrosequencing-tailored nucleotide barcode design unveils opportunities for large-scale sample multiplexing. Nucleic Acids Research, 35(19):e130, 2007.

[78] K. Pearson. Mathematical Contributions to the Theory of Evolution.-On a Form of Spurious Correlation Which May Arise When Indices Are Used in the Measurement of Organs. Proceedings of the Royal Society of London, 60:489-498, 1896. 
[79] C. Petri. Relação entre níveis de significância bayesiano e freqüentista: e-value e p-value em tabelas de contingência. Master's thesis, IME - USP, Feb 2007.

[80] T. R. C. Read. Small-sample comparisons for the power divergence goodness-of-fit statistics. J. Am. Stat. Assoc., 79(388):929-935, 1984.

[81] K. Ribichich, S. Salem-Izacc, R. Georg, R. Vencio, L. Navarro, and S. Gomes. Gene Discovery and Expression Profile Analysis through Sequencing of Expressed Sequence Tags from Different Developmental Stages of the Chytridiomycete Blastocladiella emersonii. Eukaryotic Cell, 4(2):455, 2005.

[82] M. Robinson and G. Smyth. Small-sample estimation of negative binomial dispersion, with applications to sage data. Biostatistics, Jan 2007.

[83] W. Rodrigues. Teste de significância em tabelas de contingência 2x2 usando o modelo logístico normal. Master's thesis, Instituto de Matemática e Estatística - Universidade de São Paulo, 2006.

[84] D. J. Stekel, Y. Git, and F. Falciani. The comparison of gene expression from multiple cdna libraries. Genome Res., 10(12):2055-61, Dec 2000.

[85] J. Stollberg, J. Urschitz, Z. Urban, and C. D. Boyd. A quantitative evaluation of sage. Genome Res., 10(8):1241-8, Aug 2000.

[86] J. F. Tocher. Pigmentation Survey Of School Children In Scotland. Biometrika, 6(2-3):130-235, 1908.

[87] V. E. Velculescu, L. Zhang, B. Vogelstein, and K. W. Kinzler. Serial analysis of gene expression. Science, 270(5235):484-487, Oct 1995.

[88] R. Vencio, L. Varuzza, C. Pereira, H. Brentani, and I. Shmulevich. Simcluster: clustering enumeration gene expression data on the simplex space. BMC Bioinformatics, 8(1):246, 2007.

[89] J. Venter, M. Adams, E. Myers, P. Li, R. Mural, G. Sutton, H. Smith, M. Yandell, C. Evans, R. Holt, et al. The Sequence of the Human Genome, 2001.

[90] R. Z. N. Vêncio, H. Brentani, D. F. C. Patrão, and C. A. de Bragança Pereira. Bayesian model accounting for within-class biological variability in serial analysis of gene expression (sage). BMC Bioinformatics, 5:119, Aug 2004.

[91] S. Wang. Understanding SAGE data. Trends in Genetics, 23:42-50, 2006.

[92] J. D. Watson and F. H. C. Crick. Molecular structure of Nucleic Acids. Nature, 171:737-738, 1953. 
[93] Y. Wong, T. Cheung, K. Lo, S. Yim, N. Siu, S. Chan, T. Ho, K. Wong, M. Yu, V. Wang, et al. Identification of molecular markers and signaling pathway in endometrial cancer in Hong Kong Chinese women by genome-wide gene expression profiling. Oncogene, 26:1971-1982, 2007.

[94] H. Working. Statistical Laws of Family Expenditure. Journal of the American Statistical Association, 38(221):43-56, 1943.

[95] C. Worth. Cairo vector graphic library, 2006. http://cairographics. org/.

[96] P. T. Xu, Y. J. Li, X. J. Qin, C. Kroner, A. Green-Odlum, H. Xu, T. Y. Wang, D. E. Schmechel, C. M. Hulette, and J. e. a. Ervin. A SAGE study of apolipoprotein E3/3, E3/4 and E4/4 allele-specific gene expression in hippocampus in Alzheimer disease. Molecular and Cellular Neuroscience, 36(3):313-331, 2007.

[97] J. Yarnold. The Minimum Expectation in $\chi^{2}$ Goodness of Fit Tests and the Accuracy of Approximations for the Null Distribution. J. Am. Stat. Assoc., 65:864-886, 1970.

[98] F. Yates. Contingency tables involving small numbers and the $\chi^{2}$ test. Journal of the Royal Statistical Society, 1(supplement):217-235, 1934.

[99] K. Yeung and W. Ruzzo. Principal component analysis for clustering gene expression data. Bioinformatics, 17(9):763-774, 2001.

[100] M. Zhang. Statistical features of human exons and their flanking regions. Human Molecular Genetics, 7(5):919-932, 1998.

[101] J. Zhu, F. He, J. Wang, and J. Yu. Modeling transcriptome based on transcript-sampling data. PLoS ONE, 3(2):e1659, Jan 2008.

[102] S. Zuyderduyn. Statistical analysis and significance testing of serial analysis of gene expression data using a poisson mixture model. BMC Bioinformatics, 8(1):282, Aug 2007. 


\section{Colophon}

Esta tese foi digitada no editor EMACS com auxilio do pacote AUCTeX. O texto composto pelo software $\mathrm{LT}_{\mathrm{E}} \mathrm{X}$, utilizando a fonte Computer Modern, ambos desenvolvidos pelo Prof. Emerito Donald Knuth. Os esquemas gráficos deste documento foram produzidos pelo pacote TikZ versão 2.00 e pelos pelos softwares gnuplot 4.2 e MATHEMATICA 6.0. Todo os programas foram executado no sistema operacional Linux Ubuntu, com excessão do MATHEMATICA, que foi executado no sistema operacional Mac OS X 10.5. 